Article

\title{
Insights into Structure and Biological Activity of Copper(II) and Zinc(II) Complexes with Triazolopyrimidine Ligands
}

\author{
Aura Argăseală ${ }^{1}$, Cătălin Maxim ${ }^{1} \mathbb{D}$, Mihaela Badea ${ }^{1} \mathbb{D}$, Larisa Ioniță ${ }^{2}$, Mariana Carmen Chifiriuc ${ }^{3,4,5}$ (D), \\ Arpad Mihai Rostas ${ }^{6,7} \mathbb{D}$, Mihaela Bacalum ${ }^{8} \mathbb{D}$, Mina Răileanu ${ }^{8,9}$, Lavinia L. Ruţă $10 \mathbb{D}^{\text {, Ileana } C . ~ F a r c a s ̧ a n u ~} 10 \mathbb{D}^{\text {, }}$ \\ Emilia Elena Iorgulescu $11, * \mathbb{D}$ and Rodica Olar 1,*D
}

check for

updates

Citation: Argăseală, A.; Maxim, C.; Badea, M.; Ioniță, L.; Chifiriuc, M.C.; Rostas, A.M.; Bacalum, M.; Răileanu, M.; Ruţă, L.L.; Farcaşanu, I.C.; et al. Insights into Structure and Biological Activity of Copper(II) and Zinc(II) Complexes with Triazolopyrimidine Ligands. Molecules 2022, 27, 765. https://doi.org/10.3390/ molecules 27030765

Academic Editor: Mauro Ravera

Received: 24 December 2021

Accepted: 22 January 2022

Published: 24 January 2022

Publisher's Note: MDPI stays neutral with regard to jurisdictional claims in published maps and institutional affiliations.

Copyright: (c) 2022 by the authors. Licensee MDPI, Basel, Switzerland. This article is an open access article distributed under the terms and conditions of the Creative Commons Attribution (CC BY) license (https:// creativecommons.org/licenses/by/ $4.0 /)$.
1 Department of Inorganic Chemistry, Faculty of Chemistry, University of Bucharest, 90-92 Panduri Str., 050663 Bucharest, Romania; aura.argaseala@s.unibuc.ro (A.A.); catalin.maxim@chimie.unibuc.ro (C.M.); mihaela.badea@chimie.unibuc.ro (M.B.)

2 Doping Control Laboratory, 37-39 Basarabia Blvd., 022103 Bucharest, Romania; l.ionita@lcd.gov.ro

3 Department of Microbiology, Faculty of Biology, University of Bucharest, 1-3 Aleea Portocalelor Str., 060101 Bucharest, Romania; carmen.chifiriuc@bio.unibuc.ro

4 Academy of Romanian Scientists, 010071 Bucharest, Romania

5 Biological Sciences Division, The Romanian Academy, 010071 Bucharest, Romania

6 Laboratory of Atomic Structures and Defects in Advanced Materials, National Institute of Materials Physics, 405A Atomiştilor Str., 077125 Măgurele-Ilfov, Romania; arpad.rostas@infim.ro

7 National Institute for Research and Development of Isotopic and Molecular Technologies, 67-103 Donat, 400293 Cluj-Napoca, Romania

8 Department of Life and Environmental Physics, Horia Hulubei National Institute for Physics and Nuclear Engineering, 30 Reactorului Str., 077125 Măgurele-Ilfov, Romania; bmihaela@nipne.ro (M.B.); mina.raileanu@nipne.ro (M.R.)

9 Department of Electricity, Solid State and Biophysics, Faculty of Physics, University of Bucharest, 405A Atomiştilor Str., 077125 Măgurele-Ilfov, Romania

10 Department of Organic Chemistry, Biochemistry and Catalysis, Faculty of Chemistry, University of Bucharest, 90-92 Panduri Str., 050663 Bucharest, Romania; lavinia.ruta@chimie.unibuc.ro (L.L.R.); ileana.farcasanu@chimie.unibuc.ro (I.C.F.)

11 Department of Analytical Chemistry, Faculty of Chemistry, University of Bucharest, 90-92 Panduri Str., 050663 Bucharest, Romania

* Correspondence: emilia-elena.iorgulescu@chimie.unibuc.ro (E.E.I.); rodica.olar@chimie.unibuc.ro (R.O.)

\begin{abstract}
In an attempt to increase the biological activity of the 1,2,4-triazolo[1,5-a]pyrimidine scaffold through complexation with essential metal ions, the complexes trans-[Cu(mptp $\left.{ }_{2} \mathrm{Cl}_{2}\right](\mathbf{1}),\left[\mathrm{Zn}(\mathrm{mptp}) \mathrm{Cl}_{2}(\mathrm{DMSO})\right](\mathbf{2})$ (mptp: 5-methyl-7-phenyl-1,2,4-triazolo[1,5-a]pyrimidine), $\left[\mathrm{Cu}_{2}(\mathrm{dmtp})_{4} \mathrm{Cl}_{4}\right] \cdot 2 \mathrm{H}_{2} \mathrm{O}(3)$ and $\left[\mathrm{Zn}(\mathrm{dmtp})_{2} \mathrm{Cl}_{2}\right]$ (4) (dmtp: 5,7-dimethyl-1,2,4-triazolo[1,5-a]pyrimidine), were synthesized and characterized as new antiproliferative and antimicrobial species. Both complexes (1) and (2) crystallize in the $P 2_{1} / \mathrm{n}$ monoclinic space group, with the tetrahedral surroundings generating a square-planar stereochemistry in the $\mathrm{Cu}$ (II) complex and a tetrahedral stereochemistry in the $\mathrm{Zn}$ (II) species. The mononuclear units are interconnected in a supramolecular network through $\pi-\pi$ interactions between the pyrimidine moiety and the phenyl ring in (1) while supramolecular chains resulting from $\mathrm{C}-\mathrm{H} \cdots \pi$ interactions were observed in (2). All complexes exhibit an antiproliferative effect against B16 tumor cells and improved antibacterial and antifungal activities compared to the free ligands. Complex (3) displays the best antimicrobial activity against all four tested strains, both in the planktonic and biofilm-embedded states, which can be correlated to its stronger DNA-binding and nuclease-activity traits.
\end{abstract}

Keywords: complex; 1,2,4-triazolo[1,5-a]pyrimidine; cytotoxicity; biofilm; metallonuclease activity

\section{Introduction}

The problems related to drug resistance in cancer and microbial infections are complex and lead to thousands of deaths each year. These adverse outcomes originate from the limitations associated with organic antibiotics [1,2] and cytostatics [3], including inorganic 
drugs like cisplatin. Cisplatin and its analogs are currently used to treat cancer, but they often lead either to severe side effects or acquired resistance [4]. As a result, the complexes bearing essential elements represent an alternative strategy to overcome these shortcomings, considering the human body's ability to manage their excess, either by storage or by excretion [5].

Among these species, complexes with $\mathrm{Cu}(\mathrm{II})$ and $\mathrm{Zn}$ (II) proved to be valuable in developing bioactive compounds with potential applications in several biomedical fields due to their antimicrobial [6-8], antitumor [8-16], antiparasitic [17], or anti-inflammatory [8] activities. These ions are usually selected for this purpose based on their low systemic toxicity, borderline acid character, and stereochemical versatility, allowing their interaction with a wide range of biomolecules in different biological systems.

Studies concerning the complexes with such ions evidenced differences concerning their mechanisms of action. Thus, while $\mathrm{Cu}$ (II) manifests both redox [18] and hydrolytic [19] abilities in a biological environment, $\mathrm{Zn}$ (II) is primarily involved in promoting the hydrolytic reactions as a result of its strong Lewis-acid character [5]. Moreover, the interaction with biomolecules can be assisted by ligands that can control both the complex stability and their interaction with aromatic components of DNA and proteins through intercalation and/or weak interactions such as dipole-dipole, electrostatic, hydrogen bonds, or $\pi-\pi$ stacking.

From this point of view, a valuable scaffold is a triazolopyrimidine-fused ring selected for biologically-active-complex development considering its resemblance to the purine bases [20] and proven ability to intercalate into DNA strands [21]. Furthermore, several complexes of $\mathrm{Cu}(\mathrm{II})$ and $\mathrm{Zn}(\mathrm{II})$ with triazolopyrimidine derivatives (tpds) have been already proven to be valuable antiparasitic, antimicrobial or antitumor species $[17,20]$.

Thus, high in vitro activity against the extracellular forms of both Leishmania spp. (promastigote) and Trypanosoma cruzi (epimastigote), coupled with a low toxicity against macrophage host cells was evidenced for M(tpds) $\mathrm{n}^{2+}$ units [M: Cu, Zn, tpds: 5,7-dimethyl1,2,4-triazolo[1,5-a]pyrimidine (dmtp) [22-24], 7-amino-1,2,4-triazolo [1,5-a]pyrimidine (7atp) [25], 5-phenyl-1,2,4-triazolo[1,5-a]pyrimidi-7(4H)-one (HftpO)] [26] or 7-amino-5methyl-1,2,4-triazolo[1,5-a]pyrimidine (7amtp) [27] and $n=2,4$ ), which are usually associated with chloride, perchlorate or nitrate counter-ions. Moreover, a series of complexes of the two metallic ions with mixed ligands, tpds and 1,10-phenanthroline (phen) [28], ethylenediamine [28] or 2,2'-bipyrimidine [29], proved to be active against the parasites responsible for leishmaniasis and Chagas disease.

Besides the antiparasitic activity, a glucose-lowering potential was recently reported for different hydrated species containing the moiety $\mathrm{Zn}(7 \mathrm{amtp})_{2} \mathrm{X} 2\left(\mathrm{X}: \mathrm{Cl}, \mathrm{NO}_{3}, \mathrm{SO}_{4}\right)$. All of these complexes present a higher selectivity index than the above-described species, and mice experiments have confirmed their ability to reduce glucose levels after oral administration [27].

A broad spectrum of antimicrobial activity against both planktonic and biofilmembedded strains, including methicillin-resistant Staphylococcus aureus (MRSA), was demonstrated by a series of complexes of 5-methyl-7-phenyl-1,2,4-triazolo[1,5-a]pyrimidine (pmtp) with the $\mathrm{M}(\mathrm{pmtp}) \mathrm{X}_{2}$ moiety ( $\mathrm{M}: \mathrm{Cu}, \mathrm{Zn} ; \mathrm{X}: \mathrm{Cl}$ [30], $\mathrm{CH}_{3} \mathrm{COO}$ [31] and $\mathrm{ClO}_{4}$ [32]). Furthermore, the $\mathrm{Cu}$ (II) species with mixed ligands, pmtp or dmtp and 2,2'-bipyridine (bpy) or 1,10-phenanthroline, showed enhanced activity in comparison with both ligands against several planktonic and biofilm-embedded bacterial strains [21,33].

The acetate and perchlorate species of $\mathrm{Cu}(\mathrm{II})$ with pmtp exhibited moderate antiproliferative activity against the human colon adenocarcinoma cell line (HT 29) [31,32]. In contrast, $\mathrm{Cu}$ (II) complexes with pmtp/dmtp and bpy/phen as auxiliary ligands exhibited excellent activity against B16 melanoma cells, accompanied by a low toxicity in eukaryotic cells $[21,33]$.

The structure for 1,2,4-triazolo[1,5-a]pyrimidine derivatives described in the paper is presented in Figure 1. 
<smiles></smiles><smiles>Oc1cc(-c2ccccc2)nc2ncnn12</smiles>

HftpO<smiles></smiles>

7 atp<smiles>Cc1cc(-c2ccccc2)nc2ncnn12</smiles>

pmtp<smiles></smiles>

7 amtp<smiles></smiles>

mptp

Figure 1. The structure for 1,2,4-triazolo[1,5-a]pyrimidine derivatives described in the paper together with IUPAC ring-numbering system.

The resistance to organic drugs observed in both pathogenic microorganisms and tumor cells as well as infections associated with microbial biofilms represent one of the main research challenges in developing new, efficient and non-toxic species. One of the most promising molecular targets is represented by DNA replication, and, in this context, high antimicrobial and antitumor activity can be exhibited by species able to interact with the DNA, which could inhibit the multiplication for both the pathogenic microorganism (in planktonic and biofilm growth state) and the neoplastic process, which is characterized by an uncontrolled cellular proliferation. A strong interaction at the DNA level can be achieved by the common action of the metal ion and the ligand.

In this context, the purpose of this paper was to combine the ability of $\mathrm{Cu}(\mathrm{II})$ and $\mathrm{Zn}$ (II) to coordinate DNA and to generate reactive oxygen species (ROS) with the capacity of tpds to establish $\pi-\pi$ stacking interactions with aromatic components of DNA. As a result, we have obtained and characterized a new series of chloride complexes of $\mathrm{Cu}(\mathrm{II})$ and $\mathrm{Zn}$ (II) with mptp and dmtp, developed as species with antiproliferative activity against B16 melanoma cells and antibiofilm activity against some pathogenic bacteria and C. albicans fungal strains. The chloride was selected as a counter-ion based on both its coordinative ability and its presence in normal biological fluids. These properties could assure an enhanced lipophilicity for neutral complexes and a low toxicity upon metabolization.

The complexes were characterized by single-crystal X-ray analyses and by different spectroscopic methods. Their stability during biological assays was proved by NMR and EPR experiments. The complexes' interaction with relevant biological systems, as well as their possible mechanisms of actions, such as their interaction with DNA and ROS release, were also investigated.

\section{Results and Discussions}

New complexes of copper(II) and zinc(II) with 5-methyl-7-phenyl-1,2,4-triazolo[1,5a]pyrimidine (mptp) were synthesized by the ligand direct reaction with metal chlorides in an ethanol-dimethylsulfoxide (DMSO) mixture, as presented in Scheme 1. Although the stoichiometric ratio between the salts and organic ligands was 1:2, in the case of $\mathrm{Zn}$ (II), the compound corresponding to the 1:1 ratio was obtained. 

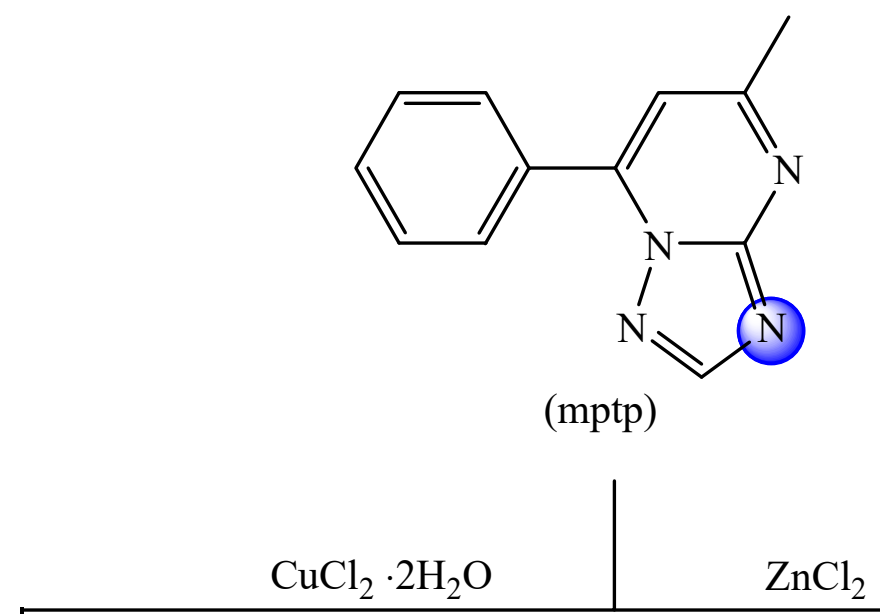

$2: 1$

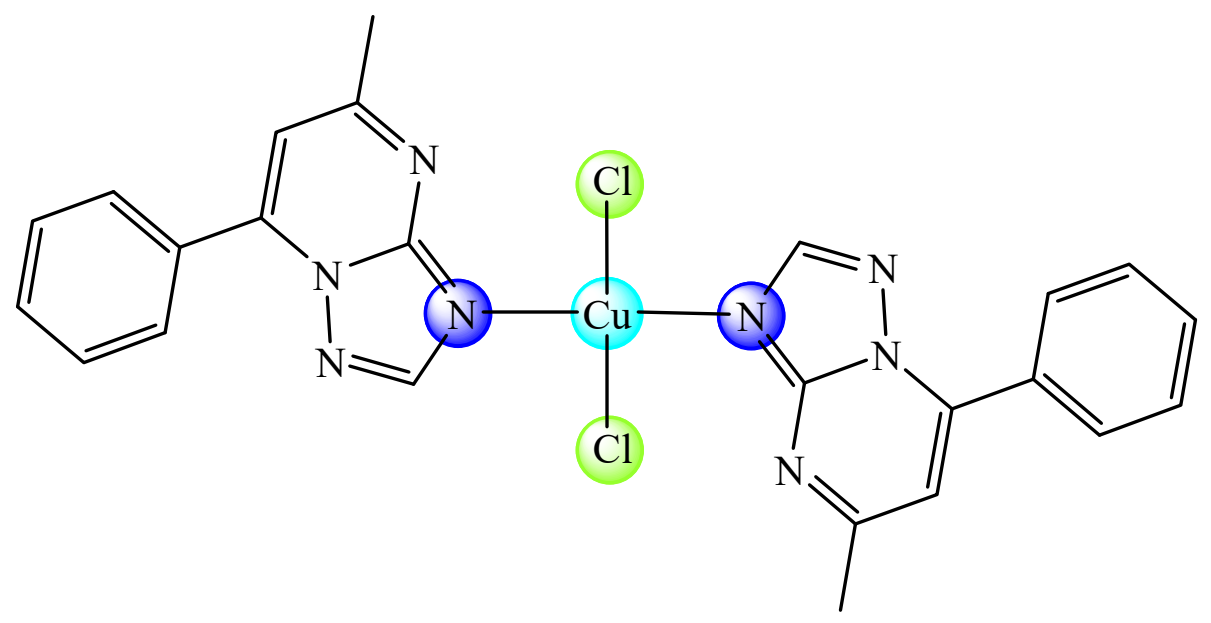

(1)
$2: 1$

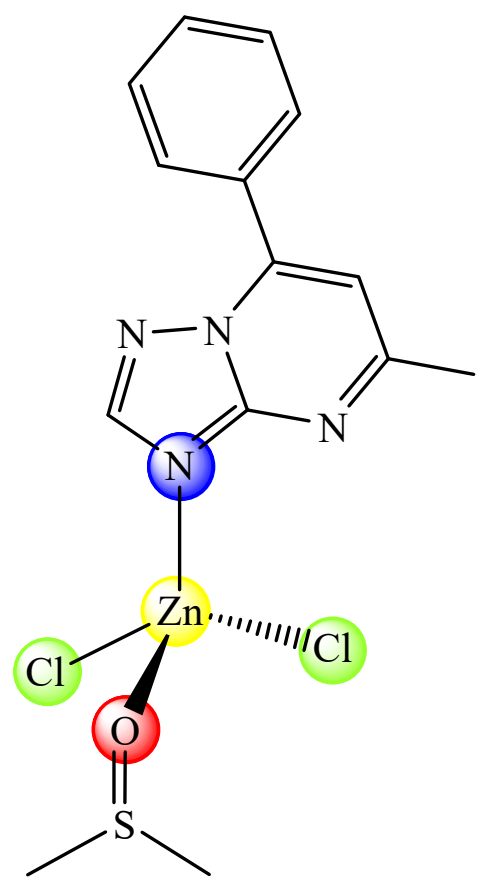

(2)

Scheme 1. The synthesis route of trans- $\left[\mathrm{Cu}(\mathrm{mptp}){ }_{2} \mathrm{Cl}_{2}\right](\mathbf{1})$ and $\left[\mathrm{Zn}(\mathrm{mptp}) \mathrm{Cl}_{2}(\mathrm{DMSO})\right](2)$.

The corresponding species with 5,7-dimethyl-1,2,4-triazolo[1,5-a]pyrimidine (dmtp) (Scheme 2) were synthesized according to a slightly modified, previously published method [22,34] in order to investigate the substituents' influence on biological activity. The new compounds were fully characterized by single-crystal X-ray diffraction. Additional data consisting of EPR, FTIR, and UV-Vis spectra and redox behavior were also collected and are discussed in the following sections. Although the complexes (3) and (4) have been already characterized from the crystallographic and spectroscopic points of view [21,33], their EPR, UV-Vis, NMR, and cyclic voltammetry data are presented here for the first time together with their antimicrobial and antiproliferative activity. 
<smiles>Cc1cc(C)n2nccc2n1</smiles>

(dmtp)

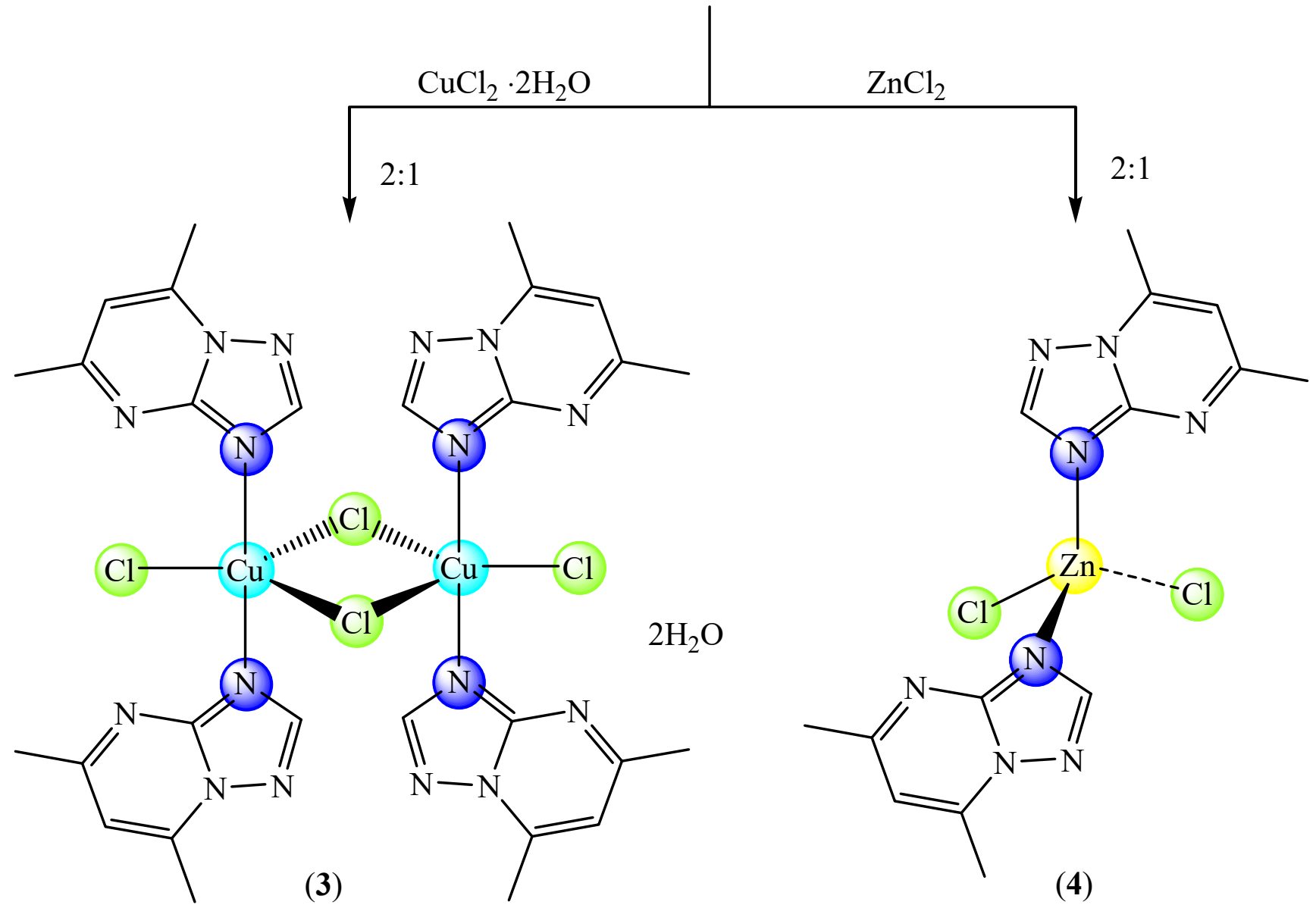

Scheme 2. The synthesis route of $\left[\mathrm{Cu}_{2}(\mathrm{dmtp})_{4} \mathrm{Cl}_{4}\right] \cdot 2 \mathrm{H}_{2} \mathrm{O}(3)$ and $\left[\mathrm{Zn}(\mathrm{dmtp})_{2} \mathrm{Cl}_{2}\right](4)$.

\subsection{Description of the Crystal Structure of Complexes}

Slow evaporation of the ethanolic solution of trans- $\left[\mathrm{Cu}(\mathrm{mptp})_{2} \mathrm{Cl}_{2}\right](\mathbf{1})$ led to a mononuclear coordination complex (Figure $2 \mathrm{a}$ ). Compound (1) crystallized in the $P 2_{1} / \mathrm{n}$ monoclinic space group, with cell parameters and structure-refinement details given in Table 1.

The asymmetric units consist of one crystallographically independent $\mathrm{Cu}$ (II) ion lying on the inversion center, one 5-methyl-7-phenyl-1,2,4-triazolo[1,5-a]pyrimidine molecule (mptp), and one chlorine ion. The Cu1 atom is tetra-coordinated, showing a slightly distorted square-planar geometry as indicated by angles of about $90^{\circ}$ around the metal ion (Supplementary Table S1). The plane of the metal ion is occupied by two nitrogen atoms from the mptp ligand [Cu1-N1 = 1.986(2) $\AA$ ], while the chlorine ligands fill the trans positions [Cu1-Cl1 = 2.2583(8) A] $($ Table 2).

Regarding the crystal-packing analysis, one can observe that the mononuclear units are interconnected through aromatic $\pi-\pi$ interactions occurring between the triazolopyrimidine ligands coordinated to the copper ions and the phenyl ring. Supramolecular chains are thus formed (Figure 2b). 
The crystal structure of compound (2) (Figure 3a) consists of mononuclear [ $\mathrm{Zn}(\mathrm{mptp}) \mathrm{Cl}_{2}$ (DMSO)] species, in which the metal ion is connected to two chlorine units, one triazoloderivative ligand, and one DMSO molecule. Each zinc(II) ion is tetra-coordinated, having a distorted tetrahedral geometry that generates the corresponding angles of $107^{\circ}$ around the metal ion (Supplementary Table S1). Therefore, two positions are occupied by two chlorine atoms $(\mathrm{Zn} 1-\mathrm{Cl} 1=2.2133(8) \AA ; \mathrm{Zn} 1-\mathrm{Cl} 2=2.2234(9) \AA)$, one imine-type nitrogen atom $(\mathrm{Zn} 1-\mathrm{N} 1=2.033(2) \AA)$, and one oxygen atom from the DMSO ligand $(\mathrm{Zn} 1-\mathrm{O} 1=1.9921(18) \AA$ ), respectively.

The crystal packing of compound (2) is governed by $\pi-\pi$ stacking interactions (Figure $3 b$ ). Thus, the mononuclear assemblies communicate through $\pi-\pi$ stacking interactions (edge to face) between the phenyl ring and the hydrogen atom from an adjacent N-heterocycle. The self-assembly of these non-covalent interactions constructs supramolecular chains running along the $b$ axis.

Table 1. Crystal data and structure refinement for compounds (1) and (2).

\begin{tabular}{|c|c|c|}
\hline Empirical Formula & $\mathrm{C}_{12} \mathrm{H}_{11} \mathrm{ClCu}_{0.5} \mathrm{~N}_{4}(1)$ & $\mathrm{C}_{14} \mathrm{H}_{17} \mathrm{Cl}_{2} \mathrm{~N}_{4} \mathrm{OSZn}$ (2) \\
\hline Formula weight & 278.48 & 425.64 \\
\hline Temperature/K & 293(2) & 293(2) \\
\hline Crystal system & monoclinic & monoclinic \\
\hline Space group & $P 2_{1} / \mathrm{n}$ & $P 2_{1} / \mathrm{n}$ \\
\hline $\mathrm{a} / \AA$ & $9.1524(12)$ & $13.1535(8)$ \\
\hline $\mathrm{b} / \AA$ & $14.0262(14)$ & $7.6713(4)$ \\
\hline $\mathrm{c} / \AA$ & $10.3212(13)$ & $18.0452(8)$ \\
\hline$\alpha /{ }^{\circ}$ & 90 & 90 \\
\hline$\beta /{ }^{\circ}$ & $115.602(15)$ & $93.025(5)$ \\
\hline$\gamma /{ }^{\circ}$ & 90 & 90 \\
\hline Volume $/ \AA^{3}$ & $1194.9(3)$ & $1818.31(16)$ \\
\hline $\mathrm{Z}$ & 4 & 4 \\
\hline$\rho_{\text {calc }} \mathrm{g} / \mathrm{cm}^{3}$ & 1.542 & 1.555 \\
\hline$\mu / \mathrm{mm}^{-1}$ & 1.166 & 1.767 \\
\hline $\mathrm{F}(000)$ & 570.0 & 868.0 \\
\hline Radiation & $(\lambda=0.71073)$ & $(\lambda=0.71073)$ \\
\hline $2 \Theta$ range for data collection $/^{\circ}$ & 5.252 to 60.824 & 3.932 to 61.588 \\
\hline Reflections collected & 4901 & 9717 \\
\hline Independent reflections & $\begin{array}{l}2570\left[R_{\text {int }}=0.0254,\right. \\
\left.R_{\text {sigma }}=0.0368\right]\end{array}$ & $\begin{array}{l}4416[\text { Rint }=0.0312, \\
\text { Rsigma }=0.0451]\end{array}$ \\
\hline Data/restraints/parameters & $2570 / 0 / 161$ & $4416 / 0 / 211$ \\
\hline Goodness-of-fit on $\mathrm{F}^{2}$ & 1.074 & 1.071 \\
\hline Final $R$ indexes $[\mathrm{I} \geq 2 \sigma(\mathrm{I})]$ & $\begin{array}{l}\mathrm{R}_{1}=0.0442 \\
\mathrm{wR}_{2}=0.1356\end{array}$ & $\begin{array}{l}\mathrm{R}_{1}=0.0386 \\
\mathrm{wR}_{2}=0.0897\end{array}$ \\
\hline Final $\mathrm{R}$ indexes [all data] & $\begin{array}{l}\mathrm{R}_{1}=0.0513 \\
\mathrm{wR} \mathrm{R}_{2}=0.1418\end{array}$ & $\begin{array}{l}\mathrm{R}_{1}=0.0643 \\
\mathrm{wR} \mathrm{R}_{2}=0.0975\end{array}$ \\
\hline Largest diff. peak/hole/e $\AA^{-3}$ & $0.66 /-0.73$ & $0.31 /-0.52$ \\
\hline
\end{tabular}




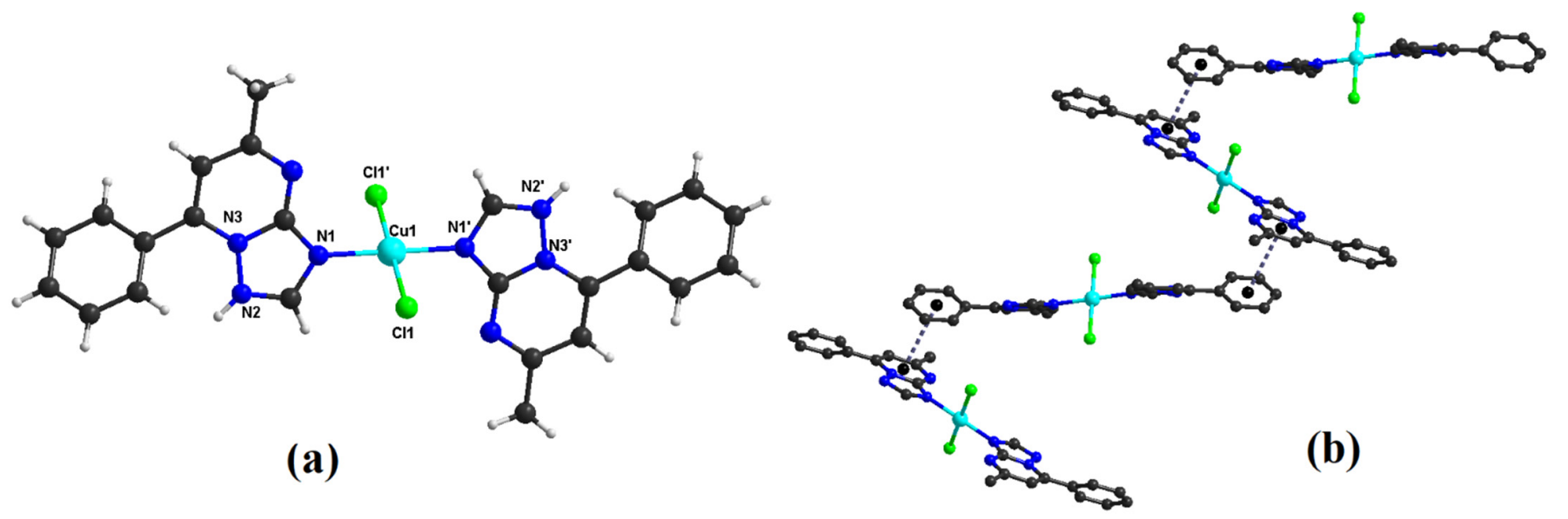

Figure 2. The crystal structure for (1) with atoms labeled (a) and the supramolecular chains in compound (1) (b).
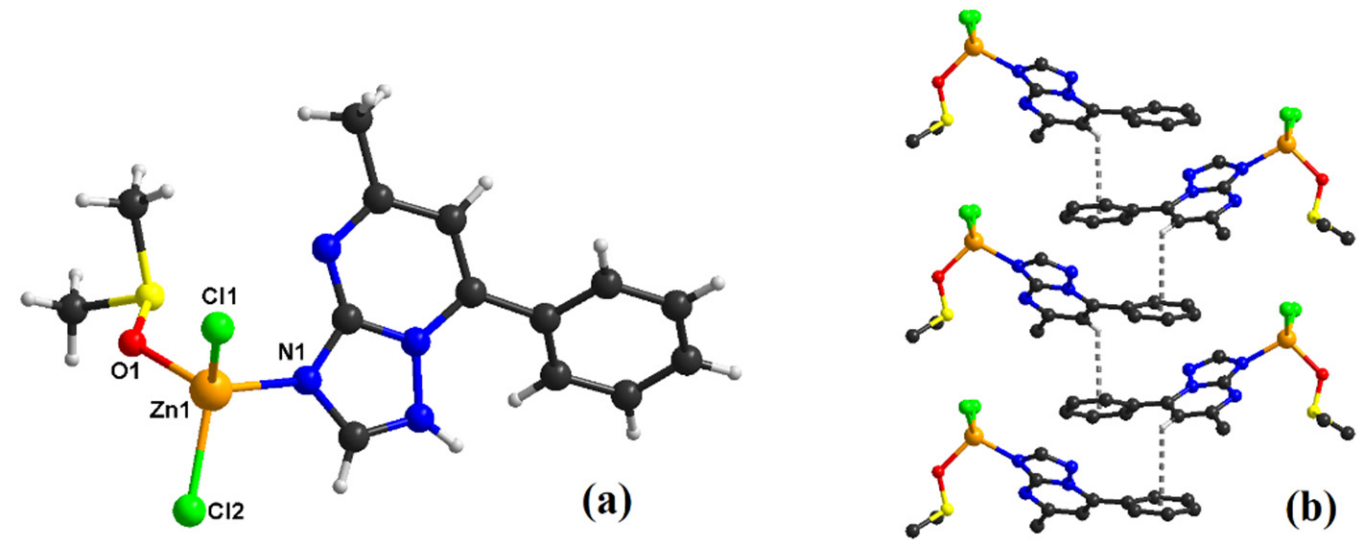

Figure 3. Crystal structure of (2): view of the asymmetric unit (a) and supramolecular chains resulting from $\mathrm{C}-\mathrm{H} \cdots \pi$ interactions $(\mathbf{b})$.

Table 2. Selected bond lengths $(\AA)$ and bond angles $\left(^{\circ}\right)$ for complexes.

\begin{tabular}{llllll}
\hline \multicolumn{2}{c}{$(\mathbf{1})$} & & \multicolumn{2}{c}{ (2) } \\
\hline $\mathrm{Cu} 1$ & $\mathrm{Cl1}{ }^{1}$ & $2.2583(8)$ & $\mathrm{Zn} 1$ & $\mathrm{Cl} 2$ & $2.2133(8)$ \\
$\mathrm{Cu} 1$ & $\mathrm{Cl} 1$ & $2.2583(8)$ & $\mathrm{Zn} 1$ & $\mathrm{Cl}$ & $2.2234(9)$ \\
$\mathrm{Cu} 1$ & $\mathrm{~N} 1$ & $1.986(2)$ & $\mathrm{Zn} 1$ & $\mathrm{~N} 1$ & $2.033(2)$ \\
$\mathrm{Cu} 1$ & $\mathrm{~N} 1{ }^{1}$ & $1.986(2)$ & $\mathrm{Zn} 1$ & $\mathrm{O} 1$ & $1.9921(18)$ \\
$\mathrm{N} 3$ & $\mathrm{~N} 2$ & $1.370(3)$ & $\mathrm{S} 1$ & $\mathrm{C} 4$ & $1.769(4)$ \\
$\mathrm{N} 3$ & $\mathrm{C} 2$ & $1.378(3)$ & $\mathrm{S} 1$ & $\mathrm{C} 6$ & $1.767(3)$ \\
$\mathrm{N} 3$ & $\mathrm{C} 7$ & $1.372(3)$ & $\mathrm{S} 1$ & $\mathrm{O} 1$ & $1.5224(19)$ \\
$\mathrm{C} 3$ & $\mathrm{C} 2$ & $1.339(4)$ & $\mathrm{N} 1$ & $\mathrm{C} 12$ & $1.352(3)$ \\
$\mathrm{C} 3$ & $\mathrm{C} 4$ & $1.330(4)$ & $\mathrm{N} 1$ & $\mathrm{C} 14$ & $1.351(3)$ \\
$\mathrm{N} 2$ & $\mathrm{C} 1$ & $1.314(4)$ & $\mathrm{N} 2$ & $\mathrm{~N} 3$ & $1.366(3)$ \\
$\mathrm{N} 1$ & $\mathrm{C} 2$ & $1.341(3)$ & $\mathrm{N} 2$ & $\mathrm{C} 14$ & $1.303(3)$ \\
\hline
\end{tabular}

Symmetry transformations used to generate equivalent atoms: ${ }^{1} 1-x, 1-y,-z$.

A comparison of the $\mathrm{M}-\mathrm{N}_{\mathrm{tpds}}$ bond lengths (Table 3 ) evidenced slightly shorter bonds for $\mathrm{Cu}$ (II) complexes (1) and (3) in comparison with the corresponding $\mathrm{Zn}$ (II) species, and a similar trend can be noticed for the mptp compounds in comparison with those bearing $\mathrm{dmtp}$ as a ligand. Instead, for unidentate chloride ligands, the $\mathrm{M}-\mathrm{Cl}$ bond lengths are shorter for the $\mathrm{Zn}$ (II) species, while the longest bond is observed in the bridge ligands $\mathrm{Cu}-\mathrm{Cl}-\mathrm{Cu}$ in complex (3). 
Table 3. The M-N and M-Cl (M: Cu, Zn) bond lengths ( $\mathrm{A})$ for complexes (1)-(4).

\begin{tabular}{llll}
\hline Compound & M-N $\mathbf{N}_{\text {tpds }}$ & $\mathbf{M}-\mathbf{C l}$ & Ref. \\
\hline$(\mathbf{1})$ & $1.986(2)$ & $2.2583(8)$ & This paper \\
\hline \multirow{2}{*}{$(\mathbf{2})$} & $2.033(2)$ & $2.2133(8)$ & This paper \\
& & $2.2234(9)$ & {$[22]$} \\
\hline \multirow{2}{*}{$(3)$} & $1.9997(15)$ & $2.2831(6)$ & \\
\hline \multirow{2}{*}{$(4)$} & $2.005(15)$ & $2.3993(6)$ & {$[34]$} \\
\hline
\end{tabular}

\subsection{Physico-Chemical Characterization of Complexes}

\subsubsection{FT-IR Spectra}

The complexes' spectra reveal the presence of two strong bands in the $1540-1635 \mathrm{~cm}^{-1}$ range, assigned to the stretching vibrations of the triazolopyrimidine moiety ( $v$ tp) and pyrimidine ring $(\nu p y m)$, respectively. These bands are slightly shifted to higher or lower wavenumbers for all complexes than for the free ligands, similar to other complexes with tpds coordinated through the $\mathrm{N}^{3}$ atom [21-33]. The additional low-intensity bands in the $455-480 \mathrm{~cm}^{-1}$ range can be assigned to the $v(\mathrm{M}-\mathrm{N})$ stretching vibration [35]. The other bands noticed at 1026 and $722 \mathrm{~cm}^{-1}$ in the complex (2) spectrum are assigned to $v(\mathrm{~S}=\mathrm{O})$ and $v(\mathrm{C}-\mathrm{S})$ vibrations for coordinated DMSO [35].

\subsubsection{UV-Vis Spectra}

A comparison of the spectra obtained for complexes (1) and (2) with those of mptp reveals that the bands assigned to the intraligand $\pi \rightarrow \pi^{*}$ transition appear at $380 \mathrm{~nm}$ in the mptp spectrum and are shifted to a lower wavelength in the complexes' spectra as a result of coordination. In the visible region of the diffuse-reflectance spectra of complex (1), an unsymmetrical absorption band split into three components with absorption maxima at 560,610 , and $660 \mathrm{~nm}$ can be noticed (Supplementary Figure S1); this pattern is characteristic to the $\mathrm{Cu}(\mathrm{II})$ ion in a distorted square-planar stereochemistry [36]. The supplementary band at $350 \mathrm{~nm}$ is assigned to ligand to metal charge transfer (LMCT) transition.

For dmtp, the $\pi \rightarrow \pi^{*}$ transition band appears at $300 \mathrm{~nm}$ with a shoulder at $490 \mathrm{~nm}$ and is similarly shifted in the complexes' spectra (Supplementary Figure S2). The spectrum of complex (3) displays the supplementary bands assigned to the $\mathrm{d}-\mathrm{d}$ transitions at 750 and $910 \mathrm{~nm}$ and the transition accounting for LMCT at $345 \mathrm{~nm}$, which is an aspect characteristic of the trigonal pyramidal environment of $\mathrm{Cu}$ (II) [36].

\subsubsection{EPR Spectroscopy}

Solid State EPR Spectroscopy

Figure 4a shows the powder EPR spectra of the two complexes (1) and (3). Both spectra present axial g-values with $\mathrm{g} \|=2.12246$ and $\mathrm{g}_{\perp}=2.0438$ for complex (1) and $\mathrm{g} \|=2.1295$ and $g_{\perp}=2.0696$ for complex (3). Because of the strong spin-spin exchange interaction, no hyperfine coupling is observable. The formation of dimers in complex (3) is evidenced by the EPR signal at half field, which is much lower in intensity and depicted in the inset of Figure 4a.

Figure $4 \mathrm{~b}-\mathrm{d}$ show the EPR spectra of a single complex (1) crystal with B0 perpendicular to the $c a, a b$, and bc planes, respectively, with rotation along the $c$, a, and $b$ axes, respectively. The spectra presented in Figure $4 b, c$ show a strong exchange interaction evidenced by a sharp EPR signal for the single-crystal oriented perpendicular to the z-axis and a weak interaction for the $90^{\circ}$ rotation along the axis mentioned above. For the orientation presented in Figure $4 \mathrm{~d}$, a strong exchange interaction is also observable for the $90^{\circ}$ position. These findings are in excellent agreement with the crystal structure shown in the inset of each figure. 

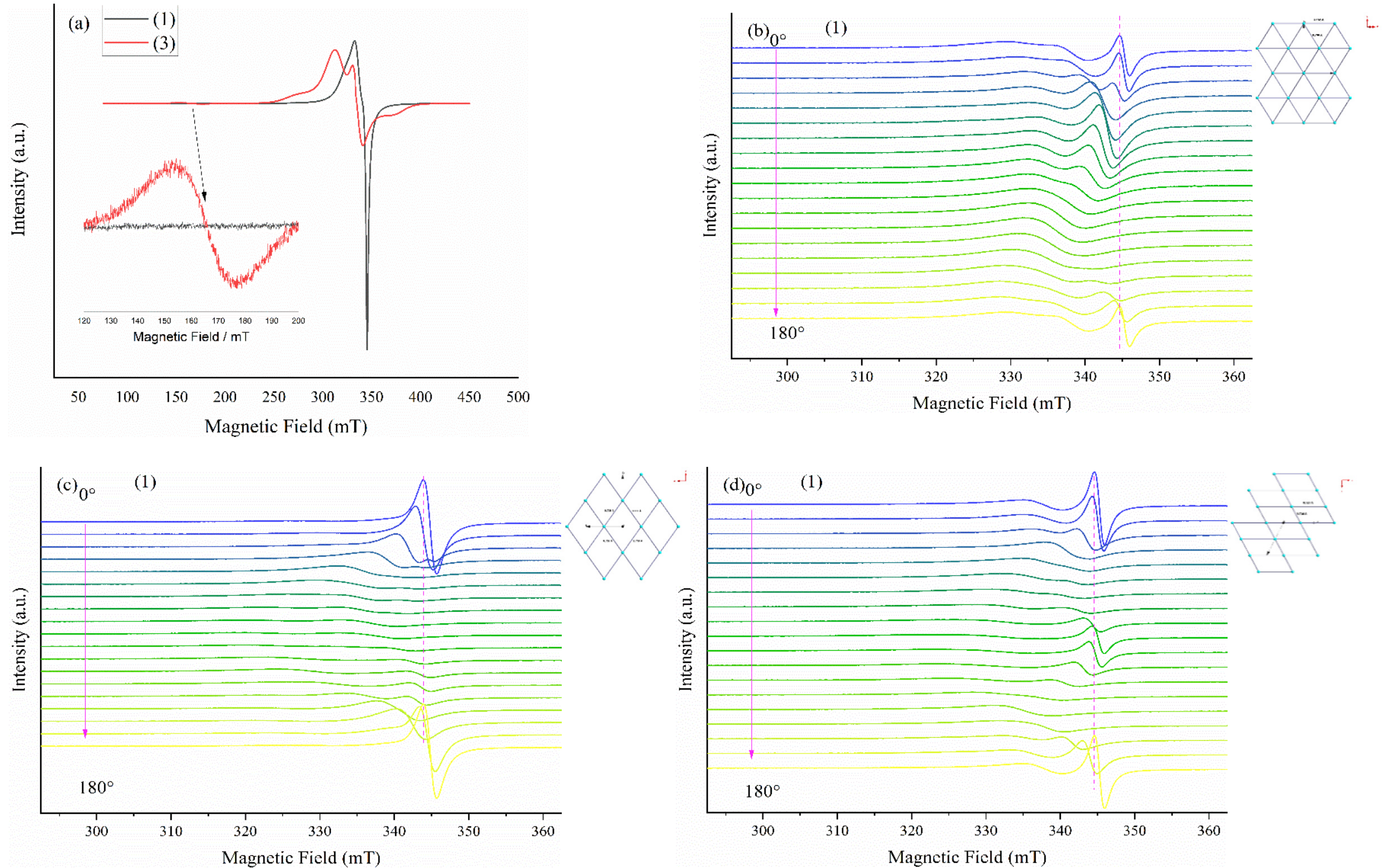

Figure 4. Powder EPR spectra of the complexes (1) and (3) at room temperature (a), EPR spectra of a single crystal of complex (1) with $\mathrm{B}_{0}$ perpendicular to the ca (b) $a b(\mathbf{c})$, and $b c(\mathbf{d})$ planes, with rotation along the $c, a$, and $b$ axes. 


\section{Solution EPR Spectroscopy}

The biological assays of the complexes were carried out in a DMSO solution and their stability was monitored over one week through the modifications in their EPR spectra. A $10 \mathrm{mM}$ solution was used for this experiment since the EPR spectra of lower concentrations showed no changes (Supplementary Figure S3) in the line width or any additional hyperfine lines. Still, the spectra had a lower signal-to-noise ratio, making the accumulation time 100 times longer. Figure 5a shows the EPR spectra of the $\mathrm{Cu}$ (II) complexes in the DMSO solution having almost identical line shapes. This behavior is predictable even if the structures of the two complexes is different, as described in the previous sections. Hence, in solution, the $\mathrm{Cu}-\mathrm{Cl}-\mathrm{Cu}$ bonds of complex (3) break, and the spin-spin interaction observed earlier disappears, leaving the copper center of complex (3) in the same conditions as that of complex (1). This aspect is in agreement with the complexes' structures described above.

The stability of complexes (1) and (3) in a DMSO solution is presented in Figure $5 \mathrm{~b}$. The line shape and intensity of the EPR spectra present no changes, showing excellent stability of the $\mathrm{Cu}(\mathrm{II})$ complexes even after this long period.
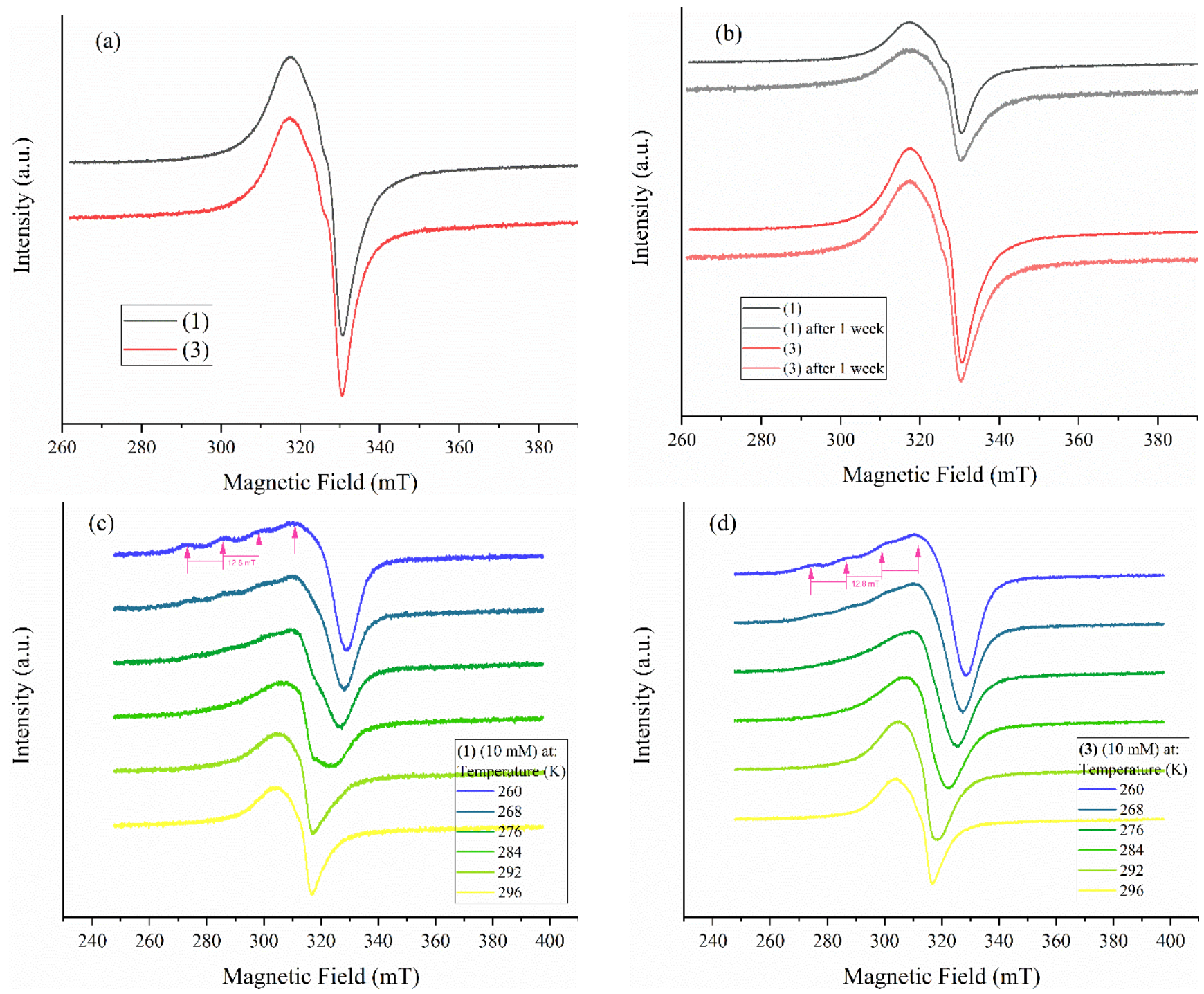

Figure 5. EPR spectra of complexes (1) and (3) in $10 \mathrm{mM}$ DMSO solution: freshly prepared (a), after one week (b), and at temperatures ranging from 260 to $296 \mathrm{~K}$ for (1) (c) and (3) (d). 
The compounds with a $10 \mathrm{mM}$ concentration were also measured at temperatures ranging from 260 to $296 \mathrm{~K}$ (Figure 4c,d). The low-temperature EPR spectra (at $260 \mathrm{~K}$ ) present the same g-values as presented in the previous section. Because of the low concentration, the hyperfine coupling is revealed with $\mathrm{A}_{\|}=12.8 \mathrm{mT}$, indicating that the structure of the complexes is maintained in the DMSO solution. The temperature sweep suggests that the mobility of the two complexes is slightly different, as evidenced by the different line shapes of the EPR spectra recorded at temperatures between 260 and $296 \mathrm{~K}$. The ligand of complex (1) is somewhat larger than that of complex (3), which directly influences its mobility in solution, and the EPR spectra become isotropic only at $296 \mathrm{~K}$ compared to complex (3), where the isotropy occurs at $284 \mathrm{~K}$. This observation is in excellent agreement with the proposed structures of the molecules.

\subsubsection{NMR Spectroscopy}

The ${ }^{1} \mathrm{H}$ NMR spectrum of (2) exhibits singlets at 2.54 and $2.68 \mathrm{ppm}$ assigned to the $\mathrm{CH}_{3}$ groups of both the DMSO and pmpt ligands. On the other hand, other signals at 8.61 and $7.54 \mathrm{ppm}$ also appear as singlets and are characteristic of the proton of the triazole and pyrimidine groups, respectively [37]. The five protons of the phenyl moiety generate a doublet at $8.15 \mathrm{ppm}$ and a multiplet at $7.64 \mathrm{ppm}$ (Supplementary Figure S4).

The ${ }^{13} \mathrm{C}$ NMR spectrum of complex (2) displays signals at $16.94\left(\mathrm{CH}_{3}\right), 24.62$ (DMSO$\mathrm{CH}_{3}$ ), 110.40, 146.17, 165.23 (pyrimidine ring), 128.65, 129.09, 129.50, 129.67, 131.53 (phenyl ring), and 155.28 ppm (triazole ring), respectively (Supplementary Figure S5).

It is worth mentioning that the DMSO presence as a ligand is responsible for the signals at $2.54 \mathrm{ppm}$ in the ${ }^{1} \mathrm{H}$ NMR spectrum and at $24.62 \mathrm{ppm}$ in the ${ }^{13} \mathrm{C}$ NMR spectrum. Moreover, the spectrum of this complex is not modified after $72 \mathrm{~h}$ (Supplementary Figure S4). The same trend was observed after $72 \mathrm{~h}$ for complex (4) (Supplementary Figure S6), indicating the complexes' stability in DMSO during the biological experiments.

The signals characteristic of the protons of triazole and pyrimidine rings appear at 7.18 and $8.56 \mathrm{ppm}$, respectively. By comparison, the signals of the two methyl groups are observed at 2.58 and $2.73 \mathrm{ppm}$ in the ${ }^{1} \mathrm{H}$ NMR spectrum of compound (4) (Supplementary Figure S6). The carbon atoms from this complex are confirmed by the signals at 16.45, $24.47\left(\mathrm{CH}_{3}\right)$, 110.90, 147.04, 164.54 (pyrimidine ring), and 155.06 ppm (triazole ring), respectively (Supplementary Figure S7).

\subsubsection{Voltammetric Studies}

The electrochemical properties of the complexes were studied by cyclic voltammetry, considering that the redox potential influences their interaction with another redox-active species in biological systems.

The study of the electrochemical behavior of the $\mathrm{Cu}(\mathrm{II})$ complexes (1) and (3) was carried out to investigate the oxidation-reduction process, in the range of $+0.10 \rightarrow+0.90 \mathrm{~V}$ $\rightarrow-1.20 \mathrm{~V}$ (Figure 6). In the positive range, the oxidation processes of $\mathrm{Cu}(\mathrm{II}) / \mathrm{Cu}$ (III) can be observed at $\mathrm{E}_{\mathrm{pa} 1}=+0.481 \mathrm{~V}$ for complex (1) and $\mathrm{E}_{\mathrm{pa} 1}=+0.583 \mathrm{~V}$ for complex (3), with values shifted to a positive range compared to those obtained for the $\left[\mathrm{Cu}(\mathrm{DMSO})_{6}\right] \mathrm{Cl}_{2}$ species, leading to higher values of $\mathrm{E}_{1 / 2}$ proper for the hydrogen peroxide reduction. Cyclic scanning between +0.90 and $-1.20 \mathrm{~V}$ shows a large reduction counter-peak at $\mathrm{E}_{\mathrm{pc} 1}=+0.200 \mathrm{~V}$ for all copper compounds (Table 4). For complex (3), a reduction wave at $\mathrm{E}_{\mathrm{pc} 2} \sim-0.800 \mathrm{~V}$ is also observed, which can be assigned to the reduction of both the ligand and $\mathrm{Cu}(\mathrm{II}) / \mathrm{Cu}(\mathrm{I})$. 


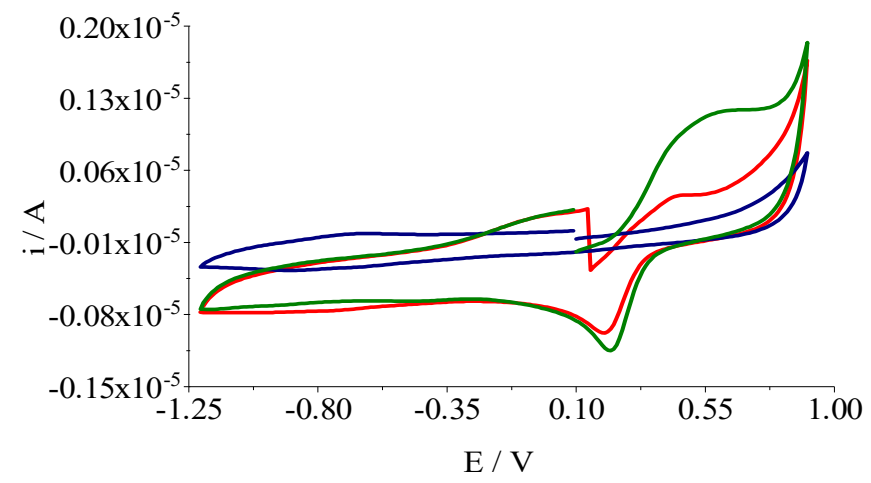

(a)

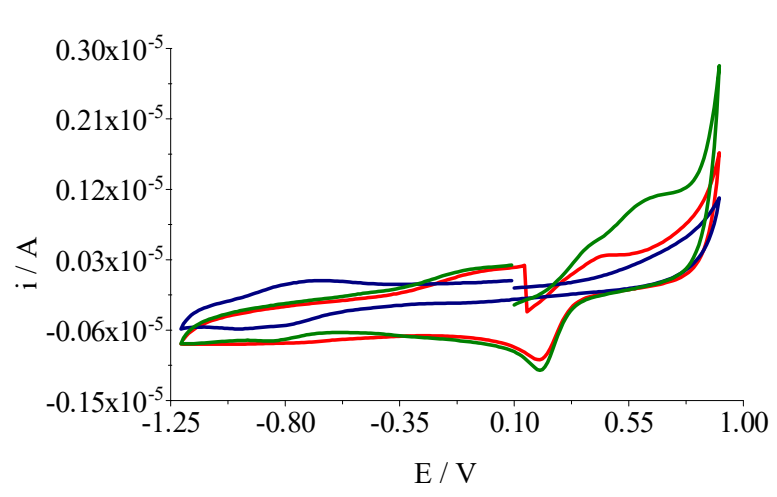

(b)

Figure 6. Cyclic voltammograms of copper complex (1) (a) and complex (3) (b), cyclic voltammograms of $\left[\mathrm{Cu}(\mathrm{DMSO})_{6}\right] \mathrm{Cl}_{2}$ (red line), ligand (blue line), complex (green line), $1 \mathrm{mM}$ in DMSO, $(0.1 \mathrm{M}$ $\mathrm{Bu}_{4} \mathrm{NClO}_{4}$; scan rate: $0.050 \mathrm{~V} / \mathrm{s}$, working electrode, platinum disk, reference electrode, $\mathrm{Ag} / \mathrm{AgCl}$ (0.1 $\mathrm{M} \mathrm{Bu}_{4} \mathrm{NClO}_{4}$ in $\left.\mathrm{DMSO}\right)$.

Table 4. Cyclic-voltammetry data for complexes (1), (3), $\left[\mathrm{Cu}(\mathrm{DMSO})_{6}\right] \mathrm{Cl}_{2}$ and, ligands mptp and dmtp.

\begin{tabular}{|c|c|c|c|c|c|}
\hline Compound & $E_{p a 1}(V)$ & $E_{p c 1}(V)$ & $E_{p c 2}(V)$ & $\mathrm{Ep}_{\mathrm{a} 2}(\mathrm{~V})$ & $\begin{array}{c}\mathrm{E}_{1 / 2}(\mathrm{~V}) * \\
(\mathrm{Cu}(\mathrm{III}) / \mathrm{Cu}(\mathrm{II}))\end{array}$ \\
\hline$\left[\mathrm{Cu}(\mathrm{DMSO})_{6}\right] \mathrm{Cl}_{2}$ & +0.421 & +0.200 & -0.766 & -0.061 & +0.311 \\
\hline mptp & - & - & -0.705 & -0.796 & \\
\hline$(\mathbf{1})$ & +0.482 & +0.220 & - & - & +0.351 \\
\hline dmtp & - & - & -0.876 & -0.705 & \\
\hline (3) & +0.583 & +0.200 & -0.846 & - & +0.391 \\
\hline
\end{tabular}

All potentials are measured in $\mathrm{V}$ vs. $\mathrm{Ag} / \mathrm{AgCl} /\left(0.1 \mathrm{Bu}_{4} \mathrm{NClO}_{4}\right.$ in DMSO $) ;{ }^{*}$ Half-wave potentials were calculated for $\mathrm{Cu}(\mathrm{III}) / \mathrm{Cu}(\mathrm{II})$ couple by using $\mathrm{E}_{1 / 2}=\left(\mathrm{E}_{\mathrm{pa} 1}+\mathrm{E}_{\mathrm{pc} 1}\right) / 2$.

Cyclic voltammetric scans of zinc complexes, $\left[\mathrm{Zn}(\mathrm{DMSO})_{4}\right] \mathrm{Cl}_{2}$ and ligands (mptp and dmtp) at a concentration of $1 \mathrm{mM}$ in DMSO using tetrabutylammonium perchlorate $\left(\mathrm{Bu}_{4} \mathrm{NClO}_{4}\right) 0.1 \mathrm{M}$ as the supporting electrolyte, with a sweep rate of $0.1 \mathrm{~V} \mathrm{~s}^{-1}$ and a glassy-carbon-disk electrode were obtained and are presented in Figure 7.

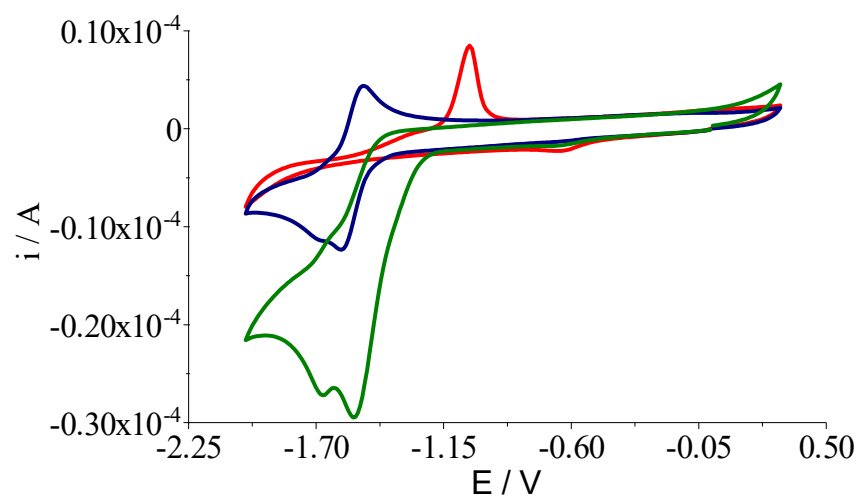

(a)

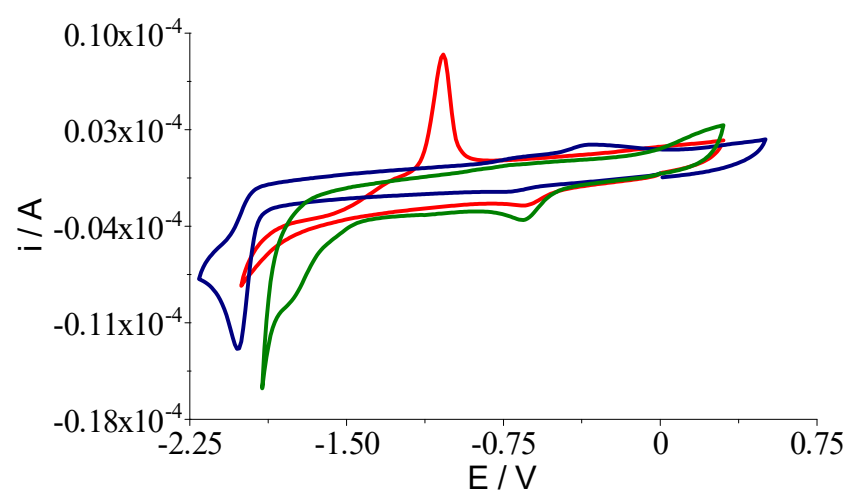

(b)

Figure 7. Cyclic voltammograms of zinc complex (2) (a) and complex (4) (b), cyclic voltammograms of $\left[\mathrm{Zn}(\mathrm{DMSO})_{4}\right] \mathrm{Cl}_{2}$ (red line), ligand (blue line), complex (green line), $1 \mathrm{mM}$ in DMSO (scan rate: $0.100 \mathrm{~V} / \mathrm{s}$, working electrode: glassy-carbon disk, reference electrode: $\mathrm{Ag} / \mathrm{AgCl}\left(0.1 \mathrm{M} \mathrm{Bu}_{4} \mathrm{NClO}_{4}\right.$ in DMSO)). 
In the case of $\left[\mathrm{Zn}(\mathrm{DMSO})_{4}\right] \mathrm{Cl}_{2}$ in DMSO solution, a two-electron reduction $\left(\mathrm{E}_{\mathrm{pc} 1}=-0.635 \mathrm{~V}\right)$ can be observed such that the back scan exhibits the typical 'anodic stripping' of the electrodeposited $\mathrm{Zn}(0)$ at $\mathrm{E}_{\mathrm{pa} 1}=-1.037 \mathrm{~V}$. The cyclic voltammograms recorded for the zinc-complex solutions (2) and (4) exhibit an irreversible reduction wave $\left(\mathrm{E}_{\mathrm{pc} 1}=0.650 \mathrm{~V}\right)$ followed by further ligand-centered irreversible processes $\left(\mathrm{E}_{\mathrm{pc} 2}=1.531 \mathrm{~V}\right.$ and $\left.\mathrm{E}_{\mathrm{pc} 2}=1.742 \mathrm{~V}\right)$, with mptp and dmtp being the electrochemically active ligands. Comparing the values of the peak potential corresponding to the $\mathrm{Zn}(\mathrm{II})$ reduction, it is evident that complexation does not render the reduction process more difficult (Table 5).

Table 5. Cyclic voltammetry data for complexes (2), (4), $\left[\mathrm{Zn}(\mathrm{DMSO})_{4}\right] \mathrm{Cl}_{2}$ and ligands mptp and dmtp.

\begin{tabular}{lllll}
\hline Compound & \multicolumn{1}{c}{$\mathbf{E}_{\mathbf{p c 1}}(\mathbf{V})$} & \multicolumn{1}{c}{$\mathbf{E}_{\mathbf{p c} 2}(\mathbf{V})$} & \multicolumn{1}{c}{$\mathbf{E}_{\mathbf{p a 1}}(\mathbf{V})$} & \multicolumn{1}{c}{$\mathbf{E}_{\mathbf{p a 2}}(\mathbf{V})$} \\
\hline$\left[\mathrm{Zn}(\mathrm{DMSO})_{4}\right]_{\mathrm{Cl}}$ & -0.654 & - & -1.037 & - \\
mptp & - & -1.591 & 1.501 & - \\
$(\mathbf{2})$ & -0.654 & -1.531 & - & - \\
dmtp & -0.725 & -2.014 & -1.924 & -0.342 \\
$(\mathbf{4})$ & -0.644 & -1.742 & - & - \\
\hline
\end{tabular}

All potentials are measured in $\mathrm{V}$ vs. $\mathrm{Ag} / \mathrm{AgCl} /\left(0.1 \mathrm{Bu}_{4} \mathrm{NClO}_{4}\right.$ in DMSO).

The zinc(II) complexes' effect on the superoxide disproportionation was evaluated by cyclic voltammetry in DMSO without de-aeration with argon. In the absence of the zinc complexes, the wave for the quasi-reversible reduction of the $\mathrm{O}_{2}$ to $\mathrm{O}_{2}{ }^{-}(\mathrm{Epc}=-0.765 \mathrm{~V}$ and Epa $=-0.664 \mathrm{~V}$, red cyclic voltammogram in Figure 8) was observed. When the zinc(II) complexes were added to the solution, the wave corresponding to the $\mathrm{O}_{2}{ }^{-}$oxidation decreased by approximately tenfold in intensity. This implies that the zinc complexes quench the superoxide in solution (blue and green cyclic voltammograms in Figure 8) [38].

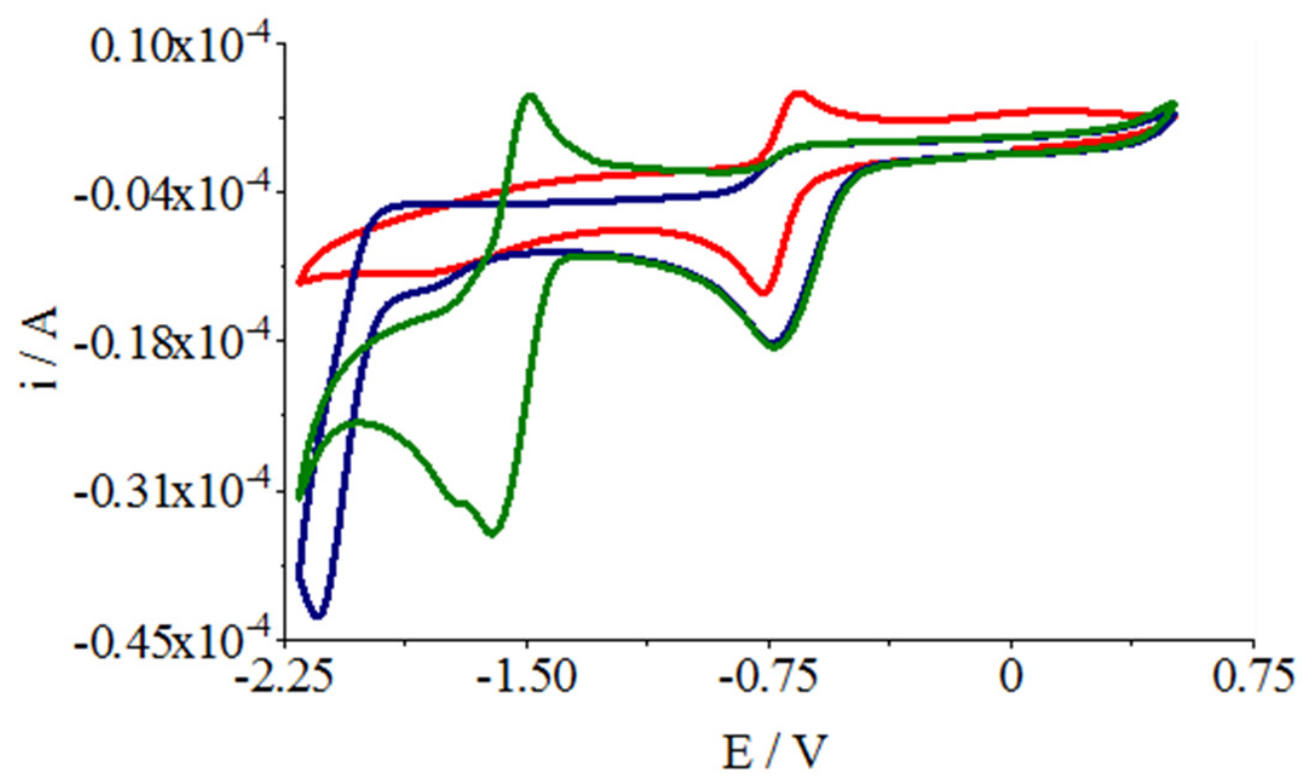

Figure 8. Cyclic voltammograms of the electrolyte solution, $0.1 \mathrm{M} \mathrm{Bu}_{4} \mathrm{NClO}_{4}$ in $\mathrm{DMSO}$ without de-aeration with argon (red line), complex (2) (green line) and complex (4) (blue line), complexes' concentration $1 \mathrm{mM}$ in DMSO without de-aeration (scan rate: $0.100 \mathrm{~V} / \mathrm{s}$, working electrode: glassycarbon disk: reference electrode, $\mathrm{Ag} / \mathrm{AgCl}\left(0.1 \mathrm{M} \mathrm{Bu}_{4} \mathrm{NClO}_{4}\right.$ in $\left.\mathrm{DMSO}\right)$ ).

\subsection{Complexes Interactions with Cells and Biological Species}

\subsubsection{Antiproliferative Activity}

The organic cytostatics used for melanoma chemotherapy generate severe side effects, including an increased risk of infection as well as resistance development. Hence, in a continuous search for new antitumor drugs with reduced side effects and lower toxicity, the $\mathrm{Cu}(\mathrm{II})$ complexes are preferred, considering their reduced systemic toxicity [18]. Thus, 
several $\mathrm{Cu}(\mathrm{II})$ species were developed as non-toxic compounds for healthy tissue but with high activity in melanoma cells [33,39,40].

The compounds reported in this study were tested against B16 cells for 24 and $48 \mathrm{~h}$, and data are presented in Figure 9. Similar to the mptp and dmtp precursors, the results show the reduced toxicity of all the complexes against the cells at concentrations below $25 \mu \mathrm{M}$. However, the viability of the cells decreased to about $80 \%$ for a concentration of $75 \mu \mathrm{M}$, indicating that the compounds reduce cell viability.

In order to determine how the compounds affect the cell morphology, the nucleus and cytoskeleton of the cells were marked for those treated with concentrations of 25 and $75 \mu \mathrm{M}$. The results presented in Figure 10 show that the morphology of the cells treated with a $25 \mu \mathrm{M}$ solution of the compounds is not changed, and a similar number of cells appears. The cells treated with $75 \mu \mathrm{M}$ also show no significant changes. However, the number of cells is reduced, indicating that the treatments kill the cells.
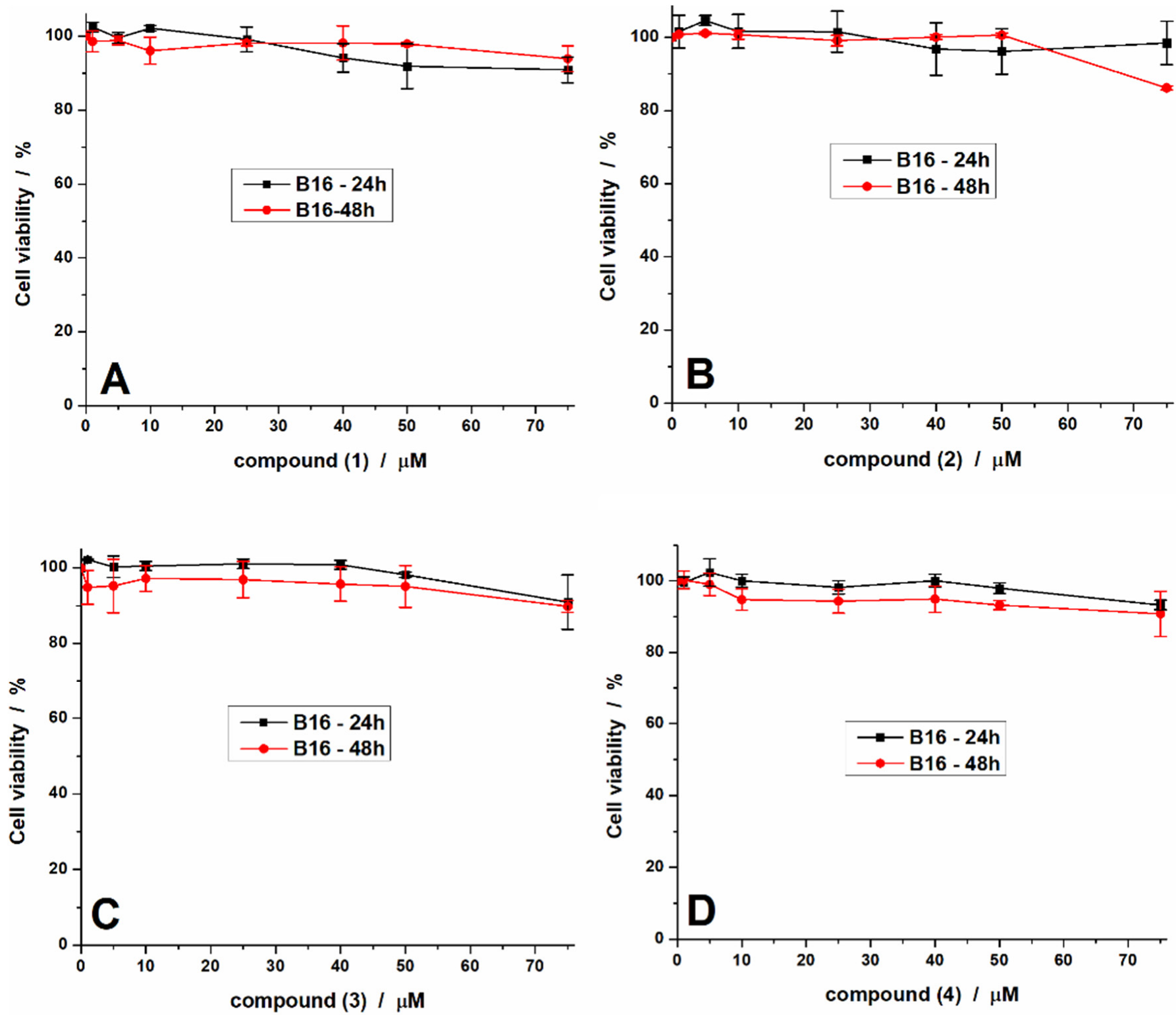

Figure 9. The cytotoxic effect of the compounds (1)—(A), (2)—(B), (3)-(C) and (4)-(D) on B16 cells evaluated after 24 and $48 \mathrm{~h}$ (each value represents the mean $\pm \mathrm{SD}$ ). 
Considering the results reported in this paper and the previous studies [21,33], we can conclude that the complexes exhibit an antiproliferative effect against the B16 tumor cells at concentrations higher than $75 \mu \mathrm{M}$. However, these concentrations are high in comparison with the half-maximal inhibitory concentration $\left(\mathrm{IC}_{50}\right)$ values recorded at $48 \mathrm{~h}$ for other species with tpds ligands, such as $\left[\mathrm{Cu}(\mathrm{N}-\mathrm{N})_{2}(\mathrm{pmtp})\right]\left(\mathrm{ClO}_{4}\right)_{2}\left(\mathrm{IC}_{50} 20.00\right.$ and $\left.4.00 \mu \mathrm{M}\right)$ [21] and $\left[\mathrm{Cu}(\mathrm{N}-\mathrm{N})(\mathrm{dmtp})_{2}\left(\mathrm{OH}_{2}\right)\right]\left(\mathrm{ClO}_{4}\right)_{2} \cdot \mathrm{dmtp}\left(\mathrm{N}-\mathrm{N}: 2,2^{\prime}\right.$-bipyridine or 1,10-phenanthroline) ( $\mathrm{IC}_{50} 4.42$ and $4.58 \mu \mathrm{M}$ ) [33]. These data suggest the necessity of a heterocyclic-derivative presence as an auxiliary ligand in complexes with tpds in order to achieve a high antiproliferative activity against B16 tumor cells.

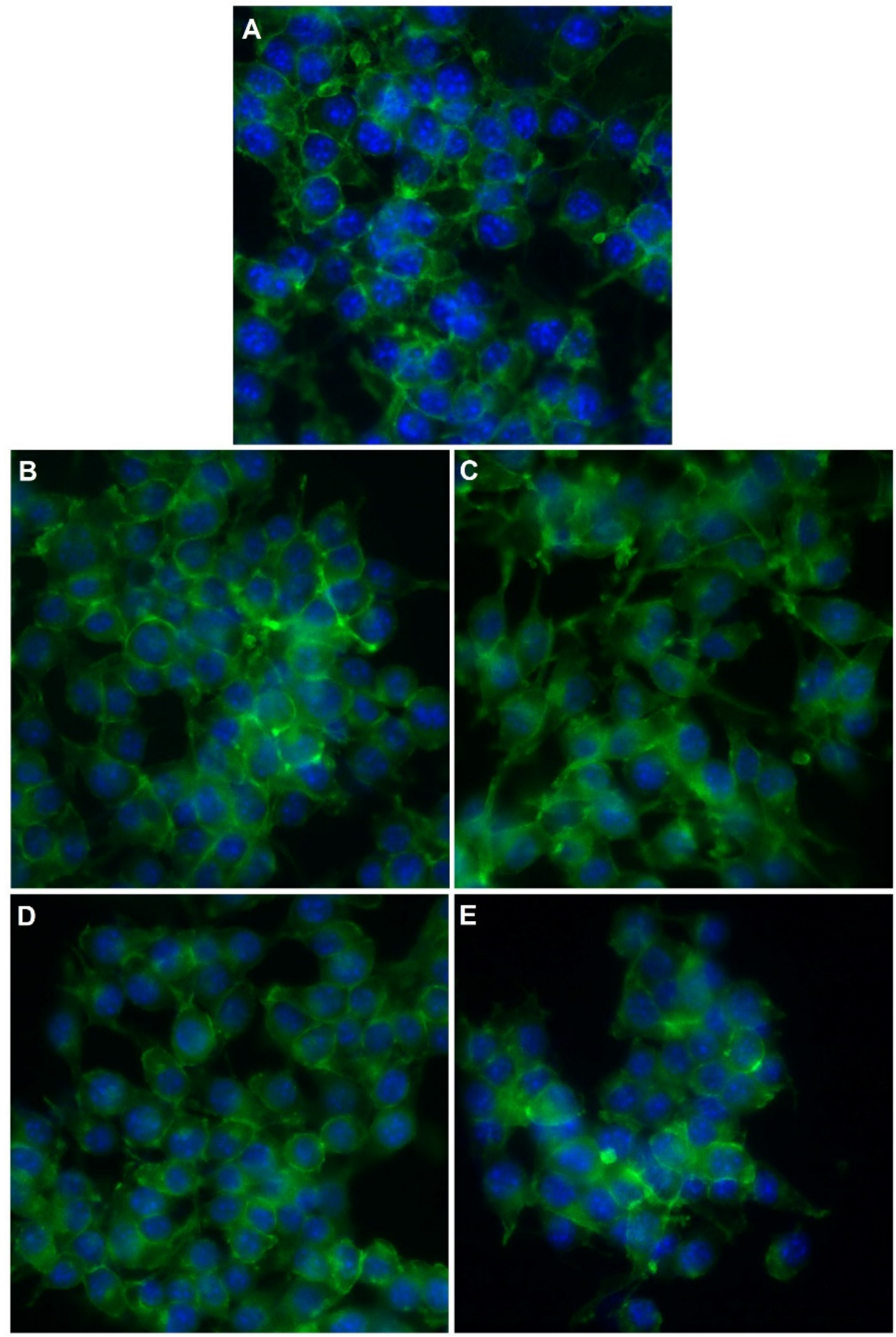

Figure 10. Cont. 

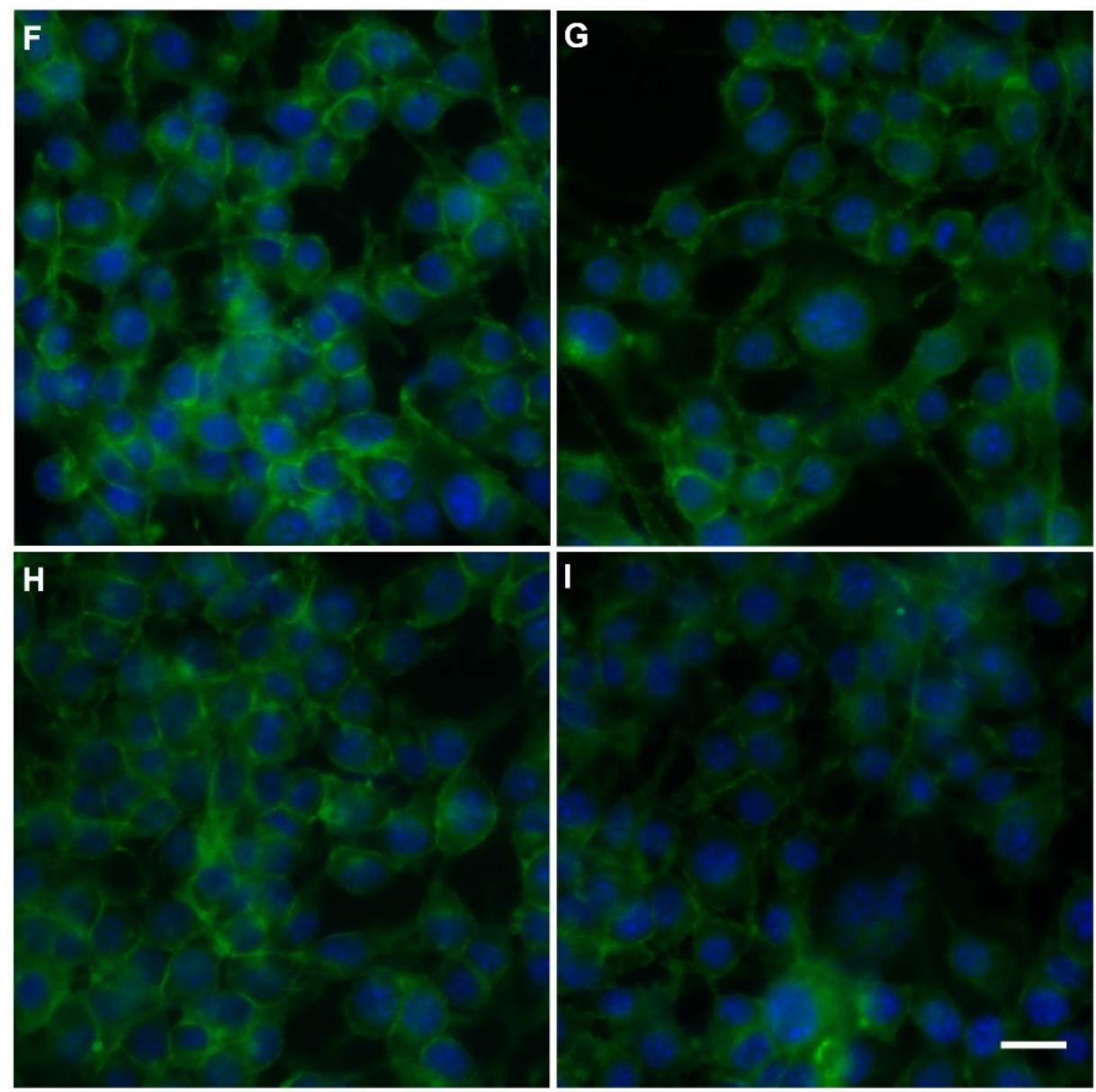

Figure 10. Cell morphology of B16 cells: control cells (A), treated with $25 \mu \mathrm{M}(\mathbf{B})$ and $75 \mu \mathrm{M}$ (C) compound (1), treated with $25 \mu \mathrm{M}$ (D) and $75 \mu \mathrm{M}$ (E) compound (2), treated with $25 \mu \mathrm{M}$ (F) and $75 \mu \mathrm{M}(\mathbf{G})$ compound (3) and treated with $25 \mu \mathrm{M}(\mathbf{H})$ and $75 \mu \mathrm{M}$ (I) compound (4) for $24 \mathrm{~h}$. Cell nuclei are stained with Hoechst 33342 (blue), and actin filaments are stained with Phalloidin-FITC (green). The scale bar is $20 \mu \mathrm{m}$ and the same for all images.

\subsubsection{Microbiological Activity}

Opportunistic infections are often a complication of oncological treatment due to the immunosuppression and intestinal dysbiosis induced by the antitumor agents [41-43]. Therefore, if the antitumor species could also exhibit an antimicrobial activity directed towards opportunistic bacterial and fungal pathogens, this could represent an advantage and would be associated with a lower risk of side effects and complications.

The antimicrobial activity of the complexes was evaluated against the Gram-negative (Klebsiella pneumoniae ATCC 134202, Pseudomonas aeruginosa ATCC 27853) and Grampositive (Bacillus subtilis ATCC 6633) reference bacterial strains, as well as the Candida albicans 22 fungal strain. The antimicrobial activity of the ligands, metal chlorides, and complexes was evaluated against planktonic and biofilm-embedded cells using quantitative assays, allowing us to establish the minimum inhibitory (MIC) and minimum biofilm eradication (MBEC) concentrations, respectively.

In the case of complexes (1) and (2), bearing the pmpt as ligand, they showed a significantly improved antibacterial activity as compared to that of the free ligand and metal salts, taking into account the much lower MIC values obtained for (1) and (2) (Table 6). Both complexes showed excellent antibacterial activity. Still, the lowest MIC values were obtained against K. pneumoniae, which is known as one of the most frequent etiological agents of opportunistic infections, such as bacteremia, in cancer patients, with worse prognoses when resistant strains are involved [44]. 
In the case of $C$. albicans 22 , only complex (2) exhibited antifungal activity.

Complexes (3) and (4), bearing dmpt as ligand, also exhibited much improved antibacterial and antifungal activity compared to the ligand. Complex (3) showed the best antimicrobial activity, as revealed by the shallow MIC values obtained for all four tested strains.

The K. pneumoniae strain proved to be the most susceptible to all four complexes, their efficiency decreasing in the following order $(4)>(3)>(2)>(1)$. However, when all four tested strains are considered, the efficiency order changes as follows $(3)>(2)>(1)>(4)$.

Table 6. The MIC values (mM) for ligand, metal chlorides, and complexes.

\begin{tabular}{lcccccccc}
\hline Bacterial Strain & $\mathbf{m p t p}$ & $\mathbf{( 1 )}$ & $\mathbf{( 2 )}$ & $\mathbf{C u C l}_{\mathbf{2}} \cdot \mathbf{2} \mathbf{H}_{\mathbf{2}} \mathbf{O}$ & $\mathbf{Z n C l}$ & $\mathbf{d m t p}$ & $\mathbf{( 3 )}$ & $\mathbf{( 4 )}$ \\
\hline K. pneumoniae 134202 & 2.38 & 0.23 & 0.15 & 5.87 & 7.35 & 3.42 & 0.14 & 0.07 \\
P. aeruginosa 27853 & 4.76 & 0.45 & - & 5.87 & 7.35 & 6.85 & 0.28 & 1.12 \\
B. subtilis 6633 & 2.38 & 0.23 & 0.29 & 5.87 & 7.35 & 3.42 & 0.14 & 0.14 \\
C. albicans 22 & - & - & 0.29 & 5.87 & 7.35 & 3.42 & 0.07 & 0.29 \\
Average MIC value & 3.173 & 0.303 & 0.243 & 5.870 & 7.350 & 4.277 & 0.158 & 0.405 \\
\hline
\end{tabular}

It is well known that both in the external environment and clinical infections, microorganisms are often adherent to different surfaces and interfaces, forming sessile, multicellular associations known as biofilms. Many mechanisms protect these communities from various limiting factors, including antimicrobial agents [45]. Therefore, in general, the anti-biofilm concentrations are much higher than those required to eradicate free microbial cells. However, in the case of our complexes, the average values were very similar, end even lower than the corresponding MIC values for complexes (1), (2), and (3).

Similar to the MIC assays, the obtained complexes showed a much more improved antibacterial and antifungal activity as compared to that of the ligand. The most susceptible biofilm was that formed by K. pneumoniae; all complexes inhibited the adherent growth with MBECs ranging from 0.04 to $0.11 \mathrm{mM}$. Regarding the other tested strains, complexes (3) and (4) were generally more active as anti-biofilm species than complexes (1) and (2), with an MBEC of $0.14 \mathrm{mM}$ for (3) and (4) against B. subtilis and of $0.07 \mathrm{mM}$ against C. albicans (Table 7). The order of the anti-biofilm activity of the four complexes was similar to that obtained for the MIC: $(3)>(2)>(1)>(4)$.

Table 7. The compounds influence on biofilm formation (MBEC value, $\mathrm{mM}$ ).

\begin{tabular}{lcccccccc}
\hline Bacterial Strain & $\mathbf{m p t p}$ & $\mathbf{( 1 )}$ & $\mathbf{( 2 )}$ & $\mathbf{C u C l}_{\mathbf{2}} \cdot \mathbf{2} \mathbf{H}_{\mathbf{2}} \mathbf{O}$ & $\mathbf{Z n C l}$ & $\mathbf{d m t p}$ & $\mathbf{( 3 )}$ & $\mathbf{( 4 )}$ \\
\hline K. pneumoniae 134202 & 2.38 & 0.11 & 0.04 & $>5.87$ & 7.35 & 3.42 & 0.07 & 0.07 \\
P. aeruginosa 27853 & 4.76 & 0.45 & - & 0.36 & 0.45 & 6.85 & 0.28 & 1.12 \\
B. subtilis 6633 & 2.38 & 0.23 & 0.29 & 5.87 & 7.35 & 3.42 & 0.14 & 0.14 \\
C. albicans 22 & - & - & 0.29 & 5.87 & 7.35 & 3.42 & 0.07 & 0.29 \\
Average MBEC value & 3.173 & 0.263 & 0.207 & 4.492 & 5.625 & 4.277 & 0.140 & 0.405 \\
\hline
\end{tabular}

Overall, these data are consistent with an enhanced activity of $\mathrm{Cu}(\mathrm{II})$ species compared to those of $\mathrm{Zn}$ (II). For both metal ions, the obtained complexes with dmtp are more active than those with the bulky mptp in the case of planktonic and biofilm-embedded strains.

Notably, high activity was recorded for the obtained complexes against K. pneumoniae, B. subtilis, and C. albicans strains that had not previously been susceptible to $\left[\mathrm{Cu}(\mathrm{N}-\mathrm{N})_{2}\right.$ (pmtp) $]\left(\mathrm{ClO}_{4}\right)_{2}$ and $\left[\mathrm{Cu}(\mathrm{N}-\mathrm{N})(\mathrm{dmtp})_{2}\left(\mathrm{OH}_{2}\right)\right]\left(\mathrm{ClO}_{4}\right)_{2} \cdot \mathrm{dmtp}$ complexes bearing tpds ligands $[21,33]$. Additionally, the activity of complex (3) against $P$. aeruginosa is enhanced in comparison with that of $\left[\mathrm{Cu}(\mathrm{N}-\mathrm{N})(\mathrm{dmtp})_{2}\left(\mathrm{OH}_{2}\right)\right]\left(\mathrm{ClO}_{4}\right)_{2} \cdot \mathrm{dmtp}$ complexes [33]. The same trend was observed concerning the anti-biofilm activity of the reported complexes. 


\subsection{Complexes Interaction with ROS}

The ability of the $\mathrm{Cu}(\mathrm{II})$ complexes to scavenge or trap reactive oxygen species (ROS) was investigated using EPR spectroscopy. A $10 \mathrm{mM}$ solution of the samples was used in combination with $\mathrm{KO}_{2}$ as an $\mathrm{O}_{2}{ }^{-}$source and $\mathrm{H}_{2} \mathrm{O}_{2}$ as an $\mathrm{OH}^{-}$source, respectively.

The EPR spectra are presented in Figure 11 and show the interaction between complexes (1) and (3) and the ROS species, as mentioned earlier. Both complexes show a meager capacity to trap or scavenge superoxide species; the intensity and shape of the EPR spectra do not change much. In contrast, both complexes show an excellent ability to trap $\mathrm{OH}^{-}$ radicals; the EPR spectra change considerably in intensity and shape.
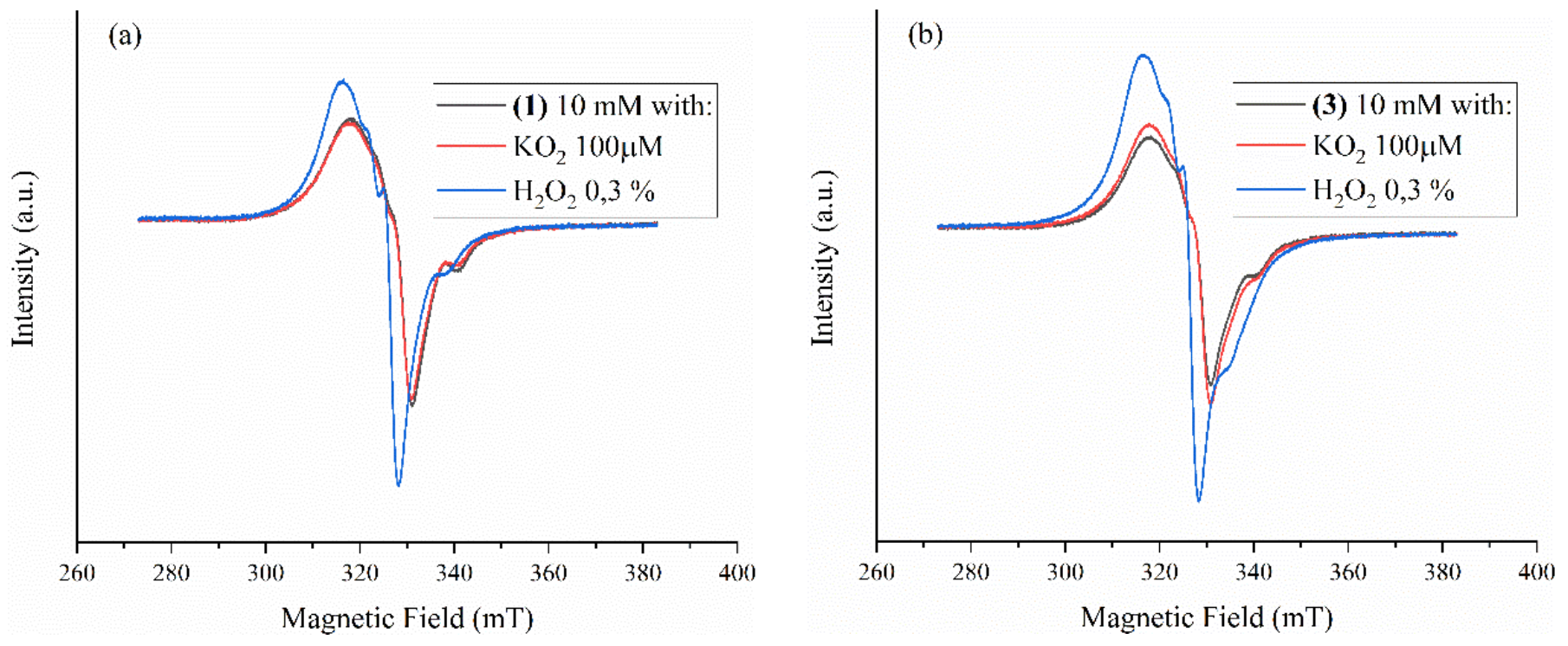

Figure 11. EPR spectra of complex (1) (a) and (3) (b) interacting with $\mathrm{KO}_{2}$ and $\mathrm{H}_{2} \mathrm{O}_{2}$ as $\mathrm{O}_{2}{ }^{-}$and $\mathrm{OH}^{-}$radical sources, respectively.

\subsection{Complexes Interaction with DNA}

In most cases, the antiproliferative and antimicrobial traits of complexes are related to their DNA-binding and DNA-cleavage capacities, respectively. To check if our complexes bind to DNA, we determined their action upon the fluorescence of the DNA/EB (ethidium bromide) adduct. Ethidium bromide is one of the most utilized dyes for DNA detection as it causes intense fluorescence increase after intercalating into the DNA duplex. If a metal complex intercalates into the DNA, it leads to a decrease in the binding sites of DNA occupied by EB, and a reduction in the fluorescence intensity of the DNA/EB system can be observed [46]. Therefore, the complexes were added to $\lambda$-DNA (DNA of bacteriophage $\lambda$ ) that was pre-treated with EB. As shown in Figure 12, both mptp (Figure 12a) and dmtp (Figure 12d) could quench the fluorescence of the $\lambda$-DNA/EB adduct, indicating that the ligands themselves may bind to DNA. The fluorescence quenching caused by the free ligands was abrupt and did not vary much with concentration. The quenching caused by the exposure to complex (1) (Figure 12b) and (4) (Figure 12f) was similar to that caused by the corresponding ligands. Complex (2) caused weaker but more nuanced quenching, which varied with increasing concentration (Figure 12c). In contrast, complex (3) had the most substantial quenching ability (Figure 12e), indicating a stronger DNA interaction. 


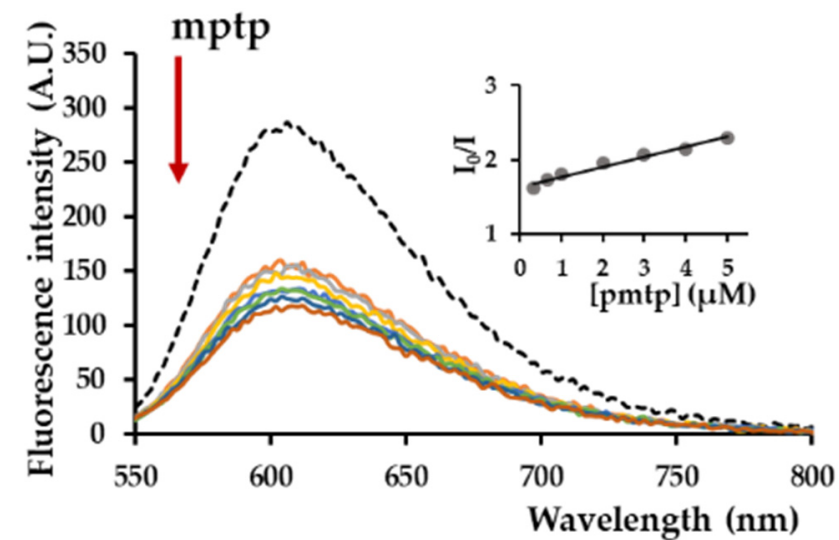

(a)

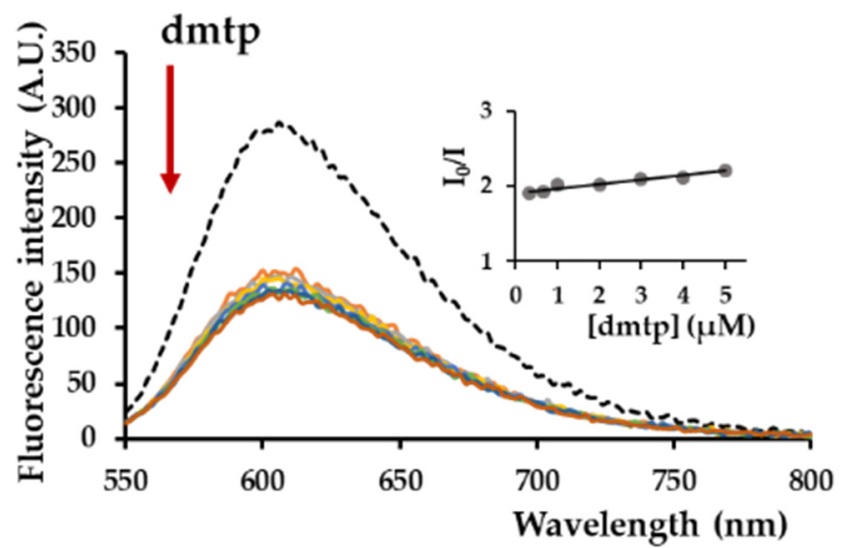

(d)

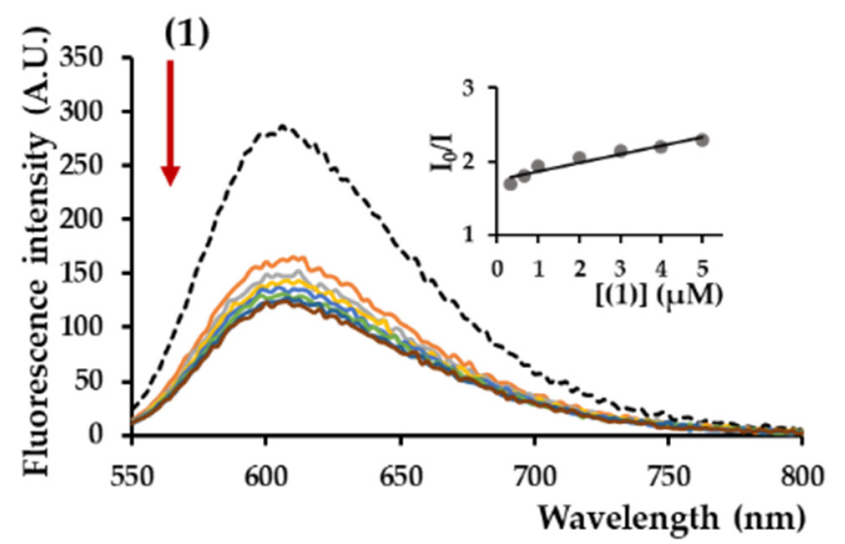

(b)

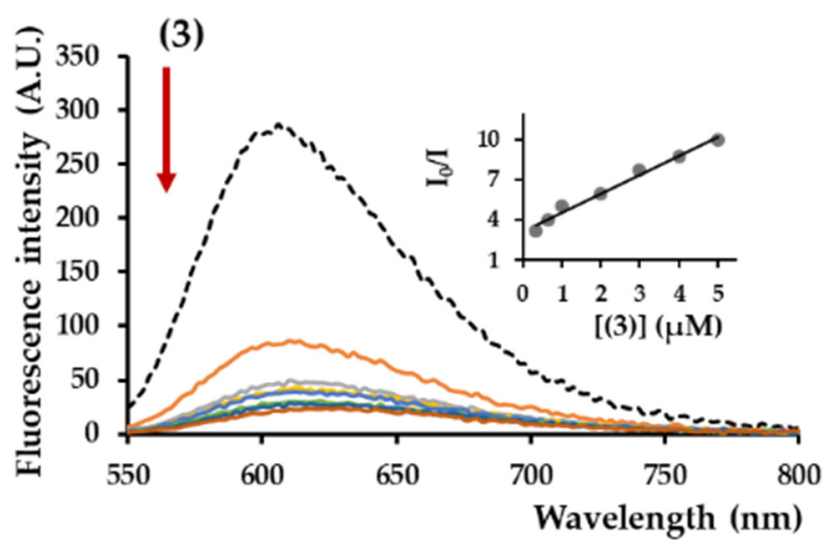

(e)

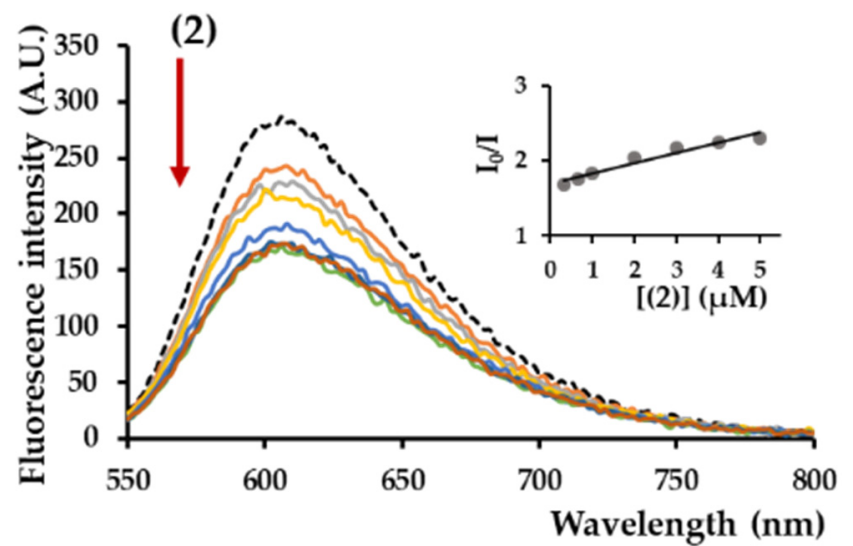

(c)

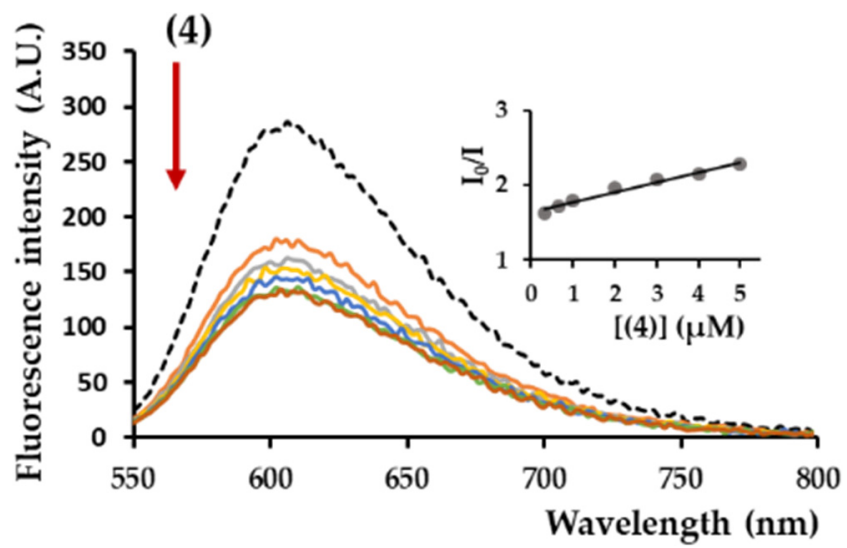

(f)

Figure 12. Fluorescence of $\lambda$-DNA/EB in the absence (black curves, dotted line) or in the presence of increasing concentrations of mptp (a); complex (1) (b); complex (2) (c); dmtp (d); complex (3) (e); complex (4) (f). Arrows indicate the quenching of the fluorescence and the increase in compound concentrations. Concentrations used: $\lambda$-DNA, $3 \mu \mathrm{M}$; EB, $1 \mu \mathrm{M}$; mptp, dmtp, (1)-(4), 1-10 $\mu \mathrm{M}$. Inset: $\mathrm{I}_{0} / \mathrm{I}$ versus [quencher]. 
The emission intensity of EtBr bound to $\lambda$-DNA was quenched upon the incremental addition of both ligands and complexes and this quenching was linear in the concentration range of $0.3-5 \mu \mathrm{M}$ (Figure 12, insets). This range of concentrations corresponds to a concentration ratio [quencher]/[DNA] of 0.1-1.66. Quenching data were analyzed according to the Stern-Volmer equation $\mathrm{I}_{0} / \mathrm{I}=1+\mathrm{K}_{\mathrm{SV}}$ [quencher] $[47,48]$, where $\mathrm{I}_{0}$ and $\mathrm{I}$ are the emission intensity in the absence and in the presence of the quencher, respectively, $\mathrm{K}_{\mathrm{SV}}$ is the Stern-Volmer constant, and [quencher] is the quencher concentration. $\mathrm{K}_{\mathrm{SV}}$ was calculated from the slope of the plot of $\mathrm{I}_{0} / \mathrm{I}$ versus [quencher] (Figure 12a-f, insets). In the linear-fit plot, the $\mathrm{K}_{\mathrm{SV}}$ determined for mptp, (1), (2), dmtp, (3), and (4) are 0.130, 0.115, 0.136, $0.056,1.412$, and $0.133 \mu \mathrm{M}^{-1}$, respectively. These results indicate that complex (3) is the best quencher of $\lambda$-DNA-EB fluorescence, probably due to a stronger DNA-intercalating trait.

The nuclease activity of complexes (1)-(4) was also tested. For this purpose, we used plasmid pUC19, which is a $2686 \mathrm{bp}$ circular plasmid. Gel electrophoresis of purified pUC19 identified two main bands belonging to the supercoiled (SC) plasmid, which migrates faster, and the nicked-circular (NC) plasmid, which migrates slower (Figure 13). It was noted that only complex (3) caused DNA relaxation to the NC form (Figure 13a). This was expected, considering the more substantial fluorescence quenching that was noted for complex (3) (Figure 12e). We also tested the effect of the concentration of (3) on the DNA-cleavage activity; we noted that the NC band intensified at 4-6 $\mu \mathrm{M}$, indicating some nuclease-like activity in this concentration range (Figure 13b).

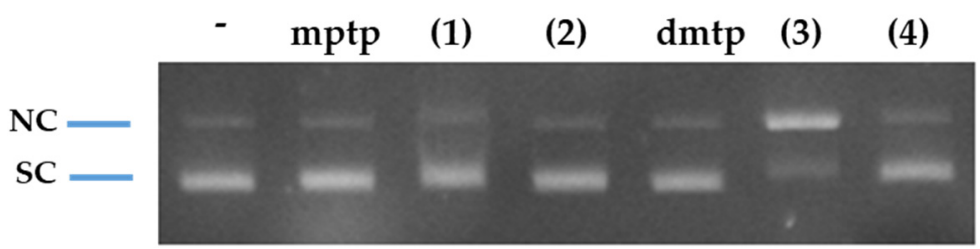

(a)

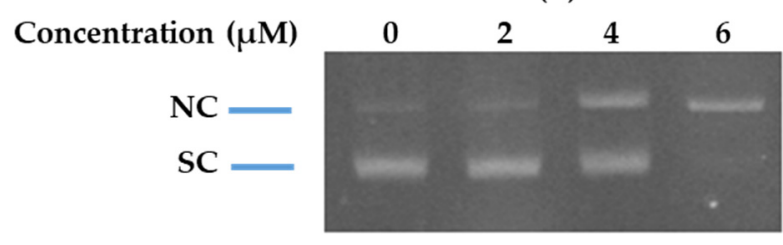

(b)

Figure 13. Gel electrophoresis image of pUC19 $(100 \mathrm{ng} / \mu \mathrm{L})$ after incubation for $1 \mathrm{~h}$ at $37^{\circ} \mathrm{C}$ with the indicated compounds. (a) Lane 1: pUC19 alone; Lanes 2-7: pUC19 $+5 \mu \mathrm{M}$ of indicated compounds. (b) Effect of (3) concentration on the relaxation of PUC19. SC, supercoiled; NC, nicked-circular.

The complexation with $\mathrm{Zn}$ (II) did not change the quenching traits of either mptp or dmtp (Figure 12a,c,d,f). Instead, the complexation with $\mathrm{Cu}(\mathrm{II})$ augmented the quenching ability of dmtp, which paralleled the onset of nuclease activity. The stronger interaction with DNA that was noticed for complex (3) may be the result of the less bulky methyl group presence, which is a characteristic that may increase its DNA-intercalating potential.

\section{Materials and Methods}

\subsection{Reagents}

The chemicals for synthesis of the complexes were purchased from Sigma-Aldrich (Darmstadt, Germany) (copper(II) chloride dihydrate ( $\geq 99.99 \%$ trace metals basis), zinc(II) chloride, 2,3-pentanedione (97\%), 1-phenyl-1,3-butanedione (99\%) and 3-amino-4H-1,2,4triazole (96\%)) and Merck (Darmstadt, Germany) (dibenzo-18-crown-6-ether, potassium superoxide) as reagent grade and were used as received, without further purification. The 5-methyl-7-phenyl-1,2,4-triazolo[1,5-a]pyrimidine (mptp) was obtained by [1+1] condensation of 3-amino-4H-1,2,4-triazole and 1-phenyl-1,3-butanedione while 5,7-dimethyl-1,2,4triazolo[1,5- $a$ ]pyrimidine (dmtp) was synthesized by [1 +1$]$ condensation of 3-amino- $4 \mathrm{H}-$ 1,2,4-triazole and 2,3-pentanedione, as was reported in the literature [49].

\subsection{Physical Measurements}

A EuroEA elemental analyzer (Perkin Elmer, Waltham, MA, USA) was used for chemical analyses $(\mathrm{C}, \mathrm{N}$, and $\mathrm{H})$. Fourier-transform-infrared-spectroscopy (FTIR) spectra were recorded in $\mathrm{KBr}$ pellets with a Tensor 37 spectrometer (Bruker, Billerica, MA, USA) in 
the $400-4000 \mathrm{~cm}^{-1}$ range. UV-Vis spectroscopy was performed in the solid state on a V 670 spectrophotometer (Jasco, Easton, MD, USA) with Spectralon as a standard in the 200-1500 nm range. The X-band Electron Paramagnetic Resonance (EPR) spectroscopy measurements were carried out with a continuous-wave X-Band Elexsys 580 EPR spectrometer (Bruker AXS GmbH, Karlsruhe, Germany) equipped with a Bruker X-SHQ 4119HS-W1 $X$-Band resonator. The measurement parameters for the X-Band measurements, if not otherwise mentioned, were set as follows: microwave frequency $9.88 \mathrm{GHz}$, microwave power $6.32 \mathrm{~mW}$, modulation amplitude $0.2 \mathrm{mT}$, conversion time $40 \mathrm{~ms}$, time constant $20.84 \mathrm{~ms}$ at 10 scans. ${ }^{1} \mathrm{H}$ NMR and ${ }^{13} \mathrm{C}$ NMR spectra were acquired by a Bruker Advance Ultrashield Plus 500 spectrometer (Bruker AXS GmbH, Karlsruhe, Germany) with a $500 \mathrm{MHz}$ working frequency at $25^{\circ} \mathrm{C}$. Chemical shifts were measured in parts per million using the internal standard tetramethylsilane (TMS). Cyclic voltammetry experiments were carried out using a three-electrode configuration consisting of a glassy-carbon or platinum (disk, $3 \mathrm{~mm}$ diameter) as a working, $\mathrm{Pt}$ wire as the counter, and $\mathrm{Ag} / \mathrm{AgCl}$ separated from the solution by a bridge filled with a $0.1 \mathrm{M} \mathrm{Bu}_{4} \mathrm{NClO}_{4}$ solution in DMSO as the reference electrode. All reported potentials are related to this reference electrode. The electrochemical measurements were performed using an Autolab PGSTAT 12, and the analysis was carried out with the GPES software. The working electrodes were polished with $0.3 \mu \mathrm{m}$ alumina powder and then rinsed with distilled water before use. All the experiments were performed at room temperature for the studies carried out in an inert atmosphere before the electrochemical scan solutions were purged with Argon (99.9999\%) for $10 \mathrm{~min}$. Tetrabutylammonium perchlorate $\left(\mathrm{Bu}_{4} \mathrm{NClO}_{4}\right) 0.1 \mathrm{M}$ was used as a supporting electrolyte.

Crystallographic data were collected with an IPDS II diffractometer (STOE, Darmstadt, Germany) having a Mo-K $\alpha(\lambda=0.71073 \AA) X$-ray tube with a graphite monochromator. A crystal of suitable size was selected from the mother liquor and immersed in paratone oil, then mounted on the tip of a glass fiber and cemented using epoxy resin. Data collection: Stoe X-AREA. Cell refinement: Stoe X-AREA [50]. The structure was solved by direct methods and refined by full-matrix least-squares techniques based on $\mathrm{F}^{2}$. The non-H atoms were refined with anisotropic displacement parameters. Calculations were performed using the SHELX-2018 crystallographic software package [51]. A summary of the crystallographic data and the final refinement details are presented in Table 1. Crystallographic data (excluding structure factors) have been deposited with the Cambridge Crystallographic Data Centre with CCDC reference numbers 2124196 and 2124197. These data can be obtained free of charge via http:/ / www.ccdc.cam.ac.uk/conts / retrieving.html (accessed on 23 December 2021), or from the Cambridge Crystallographic Data Centre, 12 Union Road, Cambridge CB2 1EZ, UK; Fax: +44-1223-336-033; or e-mail: deposit@ccdc.cam.ac.uk.

\subsection{Synthesis and Characterization of the Complexes}

$\left[\mathrm{Cu}(\mathrm{mptp}){ }_{2} \mathrm{Cl}_{2}\right](\mathbf{1})$ : To a solution containing copper(II) chloride dihydrate $(0.085 \mathrm{~g}$, $0.5 \mathrm{mmol})$ in $25 \mathrm{~mL}$ ethanol, a solution containing mptp $(0.210 \mathrm{~g}, 1 \mathrm{mmol})$ and $0.1 \mathrm{~mL}$ DMSO in $30 \mathrm{~mL}$ ethanol was added. This mixture was magnetically stirred at $50{ }^{\circ} \mathrm{C}$ for $4 \mathrm{~h}$ and then filtered for green-precipitate removal. Blue crystals suitable for X-ray analysis were obtained after one month by slow evaporation of the obtained green solution. Analysis found: $\mathrm{C}, 43.83 ; \mathrm{H}, 3.75 ; \mathrm{N}, 21.68 \%$; calculated for $\mathrm{CuC}_{24} \mathrm{H}_{20} \mathrm{~N}_{8} \mathrm{Cl}_{2}\left(\mathrm{M}_{\mathrm{W}}\right.$ : $\left.554.92 \mathrm{~g} \mathrm{~mol}^{-1}\right)$ : C, 51.95; H, 3.63; N, 20.19\%, IR (KBr pellet, $\left.\mathrm{cm}^{-1}\right): v(\mathrm{CH}), 3137 \mathrm{w} ; v_{\text {asym }}\left(\mathrm{CH}_{3}\right), 2920 \mathrm{w}$; $v_{\text {sym }}\left(\mathrm{CH}_{3}\right), 2870 \mathrm{w} ; v(\mathrm{C}=\mathrm{N})_{\operatorname{trp}}, 1615 \mathrm{~m} ; v(\mathrm{C}=\mathrm{N})_{\text {pym }}, 1543 \mathrm{vs} ; \mathrm{v}(\mathrm{Cu}-\mathrm{N}), 461 \mathrm{w}, \mathrm{UV}-\mathrm{Vis}$ (solid, $\mathrm{nm}): \pi \rightarrow \pi^{*}, 285 ;$ CTLM, 360; $\mathrm{d}_{\mathrm{x} 2-\mathrm{y} 2} \rightarrow \mathrm{d}_{\mathrm{xy}}, 560 ; \mathrm{d}_{\mathrm{xz}} \rightarrow \mathrm{d}_{\mathrm{xy}}, 610 ; \mathrm{d}_{\mathrm{z} 2} \rightarrow \mathrm{d}_{\mathrm{xy}}, 660$.

[Zn(mptp)(DMSO)Cl 2 (2): To a solution containing zinc(II) chloride $(0.068 \mathrm{~g}, 0.5 \mathrm{mmol})$ in $25 \mathrm{~mL}$ ethanol, a solution containing mptp $(0.210 \mathrm{~g}, 1 \mathrm{mmol})$ and $0.1 \mathrm{~mL}$ DMSO in $30 \mathrm{~mL}$ ethanol was added and the mixture was magnetically stirred at $50{ }^{\circ} \mathrm{C}$ for $4 \mathrm{~h}$. The solution was filtered in order to remove the yellow, sparingly soluble species, and by slow evaporation of the yellow solution, crystals suitable for X-ray analysis were obtained after one month. Analysis found: C, 39.63; H, 3.75; N, 13.25; S, 7.46\%; calculated for 
$\mathrm{ZnC}_{14} \mathrm{H}_{16} \mathrm{~N}_{4} \mathrm{SOCl}_{2}\left(\mathrm{M}_{\mathrm{w}}: 424.69 \mathrm{~g} \mathrm{~mol}^{-1}\right): \mathrm{C}, 39.59 ; \mathrm{H}, 3.80 ; \mathrm{N}, 13.19 ; \mathrm{S}, 7.55 \%$, IR (KBr pellet, $\left.\mathrm{cm}^{-1}\right)$ : v(CH), $3137 \mathrm{w}, 3110 \mathrm{w}, 3078 \mathrm{w}$; vasym $\left(\mathrm{CH}_{3}\right), 2916 \mathrm{w} ; v_{\text {sym }}\left(\mathrm{CH}_{3}\right), 2886 \mathrm{w}$; $v(\mathrm{C}=\mathrm{N})_{\text {trp }}, 1616 \mathrm{vs} ; \mathrm{v}(\mathrm{C}=\mathrm{N})_{\text {pym }}, 1544 \mathrm{vs} ; v(\mathrm{~S}=\mathrm{O}), 1026 \mathrm{~m} ; v(\mathrm{C}-\mathrm{S}), 722 \mathrm{w} ; v(\mathrm{Cu}-\mathrm{N}), 457 \mathrm{w}$, UV-Vis (solid, nm): $\pi \rightarrow \pi^{*}, 335 ;{ }^{1} \mathrm{H}$ NMR (500 Mz, DMSO d 6 , ppm): 2.54 (s, $3 \mathrm{H}, \mathrm{CH}_{3}-$ DMSO), $2.68\left(\mathrm{~s}, 3 \mathrm{H}, \mathrm{CH}_{3}\right), 7.54\left(\mathrm{~s}, \mathrm{H}, \mathrm{CH}_{\text {pyrim }}\right), 7.64\left(\mathrm{~m}, 3 \mathrm{H}, \mathrm{CH}_{\mathrm{ph}}\right), 8.15\left(\mathrm{~d}, 2 \mathrm{H}, \mathrm{CH}_{\mathrm{ph}}\right), 8.61$ (s, $\left.\mathrm{H}, \mathrm{CH}_{\text {triaz }}\right) ;{ }^{13} \mathrm{C}$ NMR (500 Mz, DMSO d 6 , ppm): $16.94\left(\mathrm{CH}_{3}\right), 24.62\left(\mathrm{CH}_{3}-\mathrm{DMSO}\right), 110.40$ (C6), 128.65, 129.09, 129.50, 129.67, 131.53 (C phenyl ring), 146.17 (C7), 155.28 ( $\left.\mathrm{C}_{\text {bridge, }} \mathrm{C} 2\right)$ and, 165.23 (C5).

$\left[\mathrm{Cu}_{2}(\mathrm{dmtp})_{4} \mathrm{Cl}_{4}\right] \cdot 2 \mathrm{H}_{2} \mathrm{O}(3)$ : The compound was synthesized as previously published [22] with slight modifications. Analysis found: $\mathrm{C}, 37.51 ; \mathrm{H}, 3.95 ; \mathrm{N}, 25.05 \%$; calculated for $\mathrm{Cu}_{2} \mathrm{C}_{28} \mathrm{H}_{36} \mathrm{~N}_{16} \mathrm{O}_{2} \mathrm{Cl}_{4}\left(\mathrm{M}_{\mathrm{w}}: 879.58 \mathrm{~g} \mathrm{~mol}^{-1}\right)$ : $\mathrm{C}, 37.47 ; \mathrm{H}, 4.04 ; \mathrm{N}, 24.97 \%$, IR (KBr pellet, $\left.\mathrm{cm}^{-1}\right)$ : $v_{\text {asym }}\left(\mathrm{H}_{2} \mathrm{O}\right), 3508 \mathrm{~s} ; v_{\text {sym }}\left(\mathrm{H}_{2} \mathrm{O}\right), 3445 \mathrm{~s} ; \mathrm{v}(\mathrm{CH}) ; v_{\text {asym }}\left(\mathrm{CH}_{3}\right), 2924 \mathrm{w} ; v_{\text {sym }}\left(\mathrm{CH}_{3}\right)$, $2856 \mathrm{w} ; \mathrm{v}(\mathrm{C}=\mathrm{N})_{\text {trp }}, 1626 \mathrm{vs} ; \mathrm{v}(\mathrm{C}=\mathrm{N})_{\text {pym }}, 1544$ vs; $v(\mathrm{Cu}-\mathrm{N}), 488 \mathrm{w}$, UV-Vis (solid, nm): $\pi \rightarrow \pi^{*}$, 270; CTLM, 345; $\mathrm{d}_{\mathrm{x} 2-\mathrm{y} 2} \rightarrow \mathrm{d}_{\mathrm{z} 2}, 750 ; \mathrm{d}_{\mathrm{xy}} \rightarrow \mathrm{d}_{\mathrm{z} 2}, 910$.

[ $\left.\mathrm{Zn}(\mathrm{dmtp})_{2} \mathrm{Cl}_{2}\right](4)$ : The compound was synthesized as previously published [22,34] with slight modifications. Analysis found: C, 42.37; H, 3.75; N, 25.90\%; calculated for $\mathrm{ZnC}_{14} \mathrm{H}_{16} \mathrm{~N}_{8} \mathrm{Cl}_{2}\left(\mathrm{M}_{\mathrm{W}}: 432.65 \mathrm{~g} \mathrm{~mol}^{-1}\right): \mathrm{C}, 38.87 ; \mathrm{H}, 3.73 ; \mathrm{N}, 25.90 \%$, IR (KBr pellet, $\left.\mathrm{cm}^{-1}\right)$ : $v(\mathrm{CH}), 3120 ; v_{\text {asym }}\left(\mathrm{CH}_{3}\right), 2957 \mathrm{w} ; v_{\text {sym }}\left(\mathrm{CH}_{3}\right), 2921 \mathrm{w} ; v(\mathrm{C}=\mathrm{N})_{\text {trp }}, 1630 \mathrm{vs} ; v(\mathrm{C}=\mathrm{N})_{\text {pym }}$, 1543 vs; $v(\mathrm{Cu}-\mathrm{N}), 487 \mathrm{w}$, UV-Vis (solid, nm): $\pi \rightarrow \pi^{*}, 270 ;{ }^{1} \mathrm{H}$ NMR $\left(500 \mathrm{Mz}, \mathrm{DMSO} \mathrm{d}_{6}\right.$, ppm): $2.58\left(\mathrm{~s}, 3 \mathrm{H}, \mathrm{CH}_{3}\right), 2.73\left(\mathrm{~s}, 3 \mathrm{H}, \mathrm{CH}_{3}\right), 7.18\left(\mathrm{~s}, \mathrm{H}, \mathrm{CH}_{\text {pyrim }}\right), 8.56\left(\mathrm{~s}, \mathrm{H}, \mathrm{CH}_{\text {triaz }}\right) ;{ }^{13} \mathrm{C}$ NMR (500 Mz, DMSO d 6 , ppm): $16.45\left(\mathrm{CH}_{3}\right), 24.47\left(\mathrm{CH}_{3}\right), 110.90$ (C6), 147.04 (C7), 155.06 ( $\left.\mathrm{C}_{\text {bridge }}, \mathrm{C} 2\right)$ and, $164.54(\mathrm{C} 5)$.

\subsection{Biological Characterization of Compounds}

\subsubsection{Screening of the Antimicrobial Properties}

The antimicrobial assays were carried out using two Gram-negative (K. pneumoniae ATCC 134202, P. aeruginosa ATCC 27853) and Gram-positive (B. subtilis ATCC 6633) reference, as well as the $C$. albicans 22 strains. The antimicrobial activity of the complexes versus the ligands and metal salts against planktonic microbial cells was assessed using the microdilution assay, allowing the MIC determination [52-54]. The anti-biofilm activity was evaluated using the crystal-violet microtiter to determine the MBEC [30-33]. All experiments were performed in triplicate. In both assays, serial binary concentrations ranging from 4.76 to $0.04 \mathrm{mM}$ were used.

\subsubsection{In Vitro Cytotoxicity Assay \\ Cell Culture Conditions}

Mouse melanoma cells (B16-ATCC CRL-6475, USA) were grown in DMEM (Dulbecco's Modified Eagle Medium) supplemented with $2 \mathrm{mM}$ L-Glutamine, $10 \%$ fetal calf serum (FCS), 100 units $/ \mathrm{mL}$ of penicillin, and $100 \mu \mathrm{g} / \mathrm{mL}$ of streptomycin at $37^{\circ} \mathrm{C}$ in a humidified incubator under an atmosphere containing $5 \% \mathrm{CO}_{2}$. All cell-cultivation media and reagents were purchased from Biochrom AG (Berlin, Germany) and Sigma-Aldrich (Darmstadt, Germany).

\section{Cell Viability Assay}

Cell viability was evaluated using 3-(4,5-dimethylthiazol-2-yl)-2,5-diphenyltetrazolium bromide (MTT) assay as previously described $[21,33]$. The influence of the tested complexes was evaluated after $24 \mathrm{~h}$ of contact with concentrations varying from 1 to $75 \mu \mathrm{M}$. The negative control was represented by cells cultivated only in medium, without the investigated compounds. The data were corrected for the background, and the percentage of viable cells was obtained using the equation:

Cell viability $=\left[\left(\mathrm{A}_{570}\right.\right.$ of treated cells $) /\left(\mathrm{A}_{570}\right.$ of untreated cells $\left.)\right] \times 100 \%$ 
The data processing was performed using Origin 8.1 (Microcal Inc. Los Angeles, CA, USA).

\section{Phalloidin Staining and Cell Imaging}

According to the manufacturer protocol, the cytoskeleton actin filaments of B16 cells were stained with phalloidin-FITC (Sigma-Aldrich, USA). Briefly, cells were washed with PBS (5 min, 3 times), fixed for 5 min with 3\% paraformaldehyde, washed three times with PBS, permeabilized with $0.1 \%$ Triton X-100 in PBS for 15 min, washed three times with PBS, stained with $20 \mu \mathrm{g} \mathrm{mL}^{-1}$ phalloidin-FITC at room temperature for $1 \mathrm{~h}$ and rewashed three times with PBS. The cell nucleus was stained with $8 \mu \mathrm{M}$ of Hoechst 33,342 solution for $10 \mathrm{~min}$, washed three times with PBS, and finally, mounted and sealed on glass slides with FluorSave $^{\mathrm{TM}}$ Reagent (Merck Millipore, Germany). The fluorescence images were acquired using an Olympus DP74 (Olympus, Germany), mounted on an epifluorescence microscope, Olympus BX-51 (Olympus, Germany), equipped with a $40 \times$ objective and an appropriate DAPI/Hoechst filter cube and GFP/FITC filter cube.

\subsubsection{Interaction with Biological Species \\ Superoxide Scavenging Ability}

The superoxide-scavenging ability of the complexes was tested using the $\mathrm{KO}_{2}$ compound as a superoxide source combined with EPR spectroscopy. To carry out the experiments, a $10 \mu \mathrm{M}$ DMSO solution of the complexes was mixed with different concentrations of $\mathrm{KO}_{2}$, and the EPR signal-intensity changes were monitored. The $\mathrm{KO}_{2}$ was dissolved by complexation with dibenzo-18-crown-6-ether.

\section{Fluorescence of $\lambda$-DNA/Ethidium Bromide Adduct}

To record the DNA/EB fluorescence spectra, we used the total DNA isolated from bacteriophage $\lambda$ ( $\lambda$-DNA, Promega, Madison, WI, USA). The binding of compounds to $\lambda$-DNA was assayed by monitoring the quenching of fluorescence emitted by $\lambda$-DNA/EB adduct $(\lambda$ excit $=510)$. The $\lambda$-DNA solution $(3 \mu \mathrm{M}$ in Tris- $\mathrm{HCl} / \mathrm{NaCl}$ buffer solution $)$ was first added to the EB solution prepared in the same buffer, then increasing concentrations of compounds (1)-(4) were added to $\lambda$-DNA/EB $[55,56]$. The fluorescence spectra were recorded in the range of 550-800 nm using a Thermo Fischer Scientific Varioskan Flash spectral scanning multimode reader (Vantaa, Vantaa, Finland). The spectra were recorded in suitable plates using $5 \mathrm{~nm}$ excitation and emission slits for all measurements.

\section{Nuclease-Like Activity Assay}

The nuclease activity of the compounds was determined using plasmid pUC19 DNA. The plasmid was amplified in Escherichia coli by transforming One Shot ${ }^{\circledR}$ TOP10 chemically competent E. coli (Invitrogen, Thermo Fisher Scientific, Waltham, MA, USA). The plasmid was isolated from positive colonies using a PureLink ${ }^{\mathrm{TM}}$ HiPure Plasmid Miniprep Kit (Invitrogen, Thermo Fisher Scientific). The plasmid (100 ng/sample) was exposed to $5 \mu \mathrm{M}$ compounds. The DNA-cleavage experiments for the complexes were performed in a 9/1 $(v / v)$ ratio of $50 \mathrm{mM}$ Tris- $\mathrm{HCl}$ buffer, $\mathrm{pH} \mathrm{8}$, and DMSO. The samples were incubated for $1 \mathrm{~h}$ at $37^{\circ} \mathrm{C}$ before a bromophenol blue/xylene cyanol-based loading dye (Roth, Germany) was added to the samples. The samples were loaded on a $1 \%(w / v)$ agarose gel containing $1 \mu \mathrm{g} / \mathrm{mL}$ EtBr in $1 \times$ TAE (Tris-acetic acid-EDTA) buffer. Electrophoresis was performed at $100 \mathrm{~V}$ for $45 \mathrm{~min}$ in $1 \times$ TAE buffer. The images of the fluorescent ethidium bromide-stained gels were captured using a gel-documentation system (Doc-Print II, VilberLourmat, France). The cleavage experiments were performed six times with similar results. One representative gel is shown. 


\section{Conclusions}

A series of complexes with 1,2,4-triazolo[1,5-a]pyrimidine derivatives was studied as potential biologically active species. Complexes (1) and (2) were fully characterized by single X-ray diffraction, a method that evidenced a square-planar stereochemistry in the $\mathrm{Cu}$ (II) complex and tetrahedral in the $\mathrm{Zn}$ (II) compound, and a supramolecular network generated by $\pi-\pi$ or $\mathrm{C}-\mathrm{H} \cdots \pi$ interactions. The EPR spectra are consistent with X-ray diffraction's stereochemistries evidenced for the $\mathrm{Cu}$ (II) ions. The complexes' stability in DMSO solution at times corresponding to biological assays was proved through EPR and NMR spectra. The complexes exhibited a moderate antiproliferative effect against the B16 tumor cells since the viability was reduced by $80 \%$ at concentrations higher than $75 \mu \mathrm{M}$. The results of antimicrobial activity demonstrate that the tested complexes exhibit significant antibacterial and antifungal activity at very low concentrations ranging from 0.04 to $0.45 \mathrm{mM}$, with complex (3) harboring the best antimicrobial and antibiofilm properties. Moreover, all complexes are very active against the K. pneumoniae strain, known as one of the most fearful etiological agents of opportunistic infections in cancer patients. The potential mechanism of action could be the nuclease-like activity of complexes, which is also supported by the complexes' ability to generate ROS. These data recommend complex (3) for further study to develop new materials with high antimicrobial activity.

Supplementary Materials: The following supporting information can be downloaded online. Figure S1: UV-Vis spectra of complexes (1) (dark blue), (2) (yellow) and mptp (black), Figure S2: UV-Vis spectra of complexes (3) (green), (4) (yellow) and dmtp (black), Figure S3: EPR spectra of complexes (1) and (3) in 1 and $10 \mathrm{mM}$ DMSO solution, Figure S4: ${ }^{1} \mathrm{H}$ NMR spectra of fresh prepared complex (2) (green) and after $72 \mathrm{~h}$ (red)., Figure S5. ${ }^{13} \mathrm{C}$ NMR spectrum of complex (2), Figure S6: ${ }^{1} \mathrm{H}$ NMR spectra of fresh prepared complex (4) (green) and after $72 \mathrm{~h}$ (red), Figure $66 .{ }^{13} \mathrm{C}$ NMR spectrum of complex (4), Table S1: Selected geometric parameters-angles $\left(^{\circ}\right)$ in compounds (1) and (2).

Author Contributions: Conceptualization, M.B. (Mihaela Badea), M.C.C., M.B. (Mihaela Bacalum), I.C.F., E.E.I. and R.O.; Data curation, A.A., C.M., M.B. (Mihaela Badea), A.M.R., M.B. (Mihaela Bacalum), M.R., L.L.R., E.E.I. and R.O.; Formal analysis, C.M., M.B. (Mihaela Badea), L.I., A.M.R., M.B. (Mihaela Bacalum), M.R., L.L.R., I.C.F., E.E.I. and R.O.; Investigation, A.A., C.M., L.I., A.M.R., M.R., L.L.R., E.E.I. and R.O.; Supervision, M.B. (Mihaela Badea), M.C.C., M.B. (Mihaela Bacalum), I.C.F. and R.O.; Validation, M.C.C., M.B. (Mihaela Bacalum) and I.C.F.; Writing—original draft, C.M., M.C.C., A.M.R., M.B. (Mihaela Bacalum), I.C.F., E.E.I. and R.O.; Writing—review and editing, M.C.C., A.M.R., I.C.F., E.E.I. and R.O. All authors have read and agreed to the published version of the manuscript.

Funding: The financial support of the University of Bucharest-UniRem 244, CNFIS-FDI-2021-0405 and C1.2.PFE-CDI.2021-587 projects are gratefully acknowledged.

Institutional Review Board Statement: Not applicable.

Informed Consent Statement: Not applicable.

Data Availability Statement: Not applicable.

Conflicts of Interest: The authors declare no conflict of interest.

Sample Availability: Samples of the compounds (1)-(4) are available from the authors.

\section{References}

1. De Oliveira, D.M.P.; Forde, B.M.; Kidd, T.J.; Harris, P.N.A.; Schembri, M.A.; Beatson, S.A.; Paterson, D.L.; Walker, M.J. Antimicrobial resistance in ESKAPE pathogens. Clin. Microbiol. Rev. 2020, 33, e00181-19. [CrossRef] [PubMed]

2. Novais, C.; Freitas, A.R. Transmission of antibiotic resistant bacteria and genes: Unveiling the jigsaw pieces of a one health problem. Pathogens 2020, 9, 497. [CrossRef] [PubMed]

3. Wang, Y.; Qin, L.; Chen, W.; Chen, Q.; Sun, J.; Wang, G. Novel strategies to improve tumour therapy by targeting the proteins MCT1, MCT4 and LAT1. Eur. J. Med. Chem. 2021, 226, 113806. [CrossRef] [PubMed]

4. $\quad$ Peng, K.; Liang, B.-B.; Liu, W.; Mao, Z.-W. What blocks more anticancer platinum complexes from experiment to clinic: Major problems and potential strategies from drug design perspectives. Coord. Chem. Rev. 2021, 449, 214210. [CrossRef] 
5. Bertini, I.; Grey, H.B.; Stiefel, E.I.; Valentine, J.S. (Eds.) Biological Inorganic Chemistry. Structure and Reactivity; University Science Books: Sausalito, CA, USA, 2007.

6. $\quad$ Liang, J.; Sun, D.; Yang, Y.; Li, M.; Li, H.; Chen, L. Discovery of metal-based complexes as promising antimicrobial agents. Eur. J. Med. Chem. 2021, 224, 113696. [CrossRef]

7. Riduan, S.N.; Zhang, Y. Recent Advances of Zinc-based Antimicrobial Materials. Chem. Asian J. 2021, 16, 1-9. [CrossRef]

8. Krasnovskaya, O.; Naumov, A.; Guk, D.; Gorelkin, P.; Erofeev, A.; Beloglazkina, E.; Majouga, A. Copper Coordination Compounds as Biologically Active Agents. Int. J. Mol. Sci. 2020, 21, 3965. [CrossRef]

9. Wehbe, M.; Leung, A.W.; Abrams, M.J.; Orvig, C.; Bally, M.B. A Perspective-Can copper complexes be developed as a novel class of therapeutics? Dalton Trans. 2017, 46, 10758-10773. [CrossRef]

10. Wang, T.; Guo, Z. Copper in Medicine: Homeostasis, Chelation Therapy and Antitumor Drug Design. Curr. Med. Chem. 2006, 13, 525-537. [CrossRef]

11. Zaki, M.; Arjmand, F.; Tabassum, S. Current and future potential of metallo drugs: Revisiting DNA-binding of metal containing molecules and their diverse mechanism of action. Inorg. Chim. Acta 2016, 444, 1-22. [CrossRef]

12. Orlov, A.P.; Orlova, M.A.; Trofimova, T.P.; Kalmykov, S.N.; Kuznetsov, D.A. The role of zinc and its compounds in leukemia. J. Biol. Inorg. Chem. 2018, 23, 347-362. [CrossRef] [PubMed]

13. Shobha Devi, C.; Thulasiram, B.; Aerva, R.R.; Nagababu, P. Recent Advances in Copper Intercalators as Anticancer Agents. J. Fluoresc. 2018, 28, 1195-1205. [CrossRef] [PubMed]

14. Gałczyńska, K.; Drulis-Kawa, Z.; Arabski, M. Antitumor Activity of Pt(II), Ru(III) and Cu(II) Complexes. Molecules 2020, $25,3492$. [CrossRef] [PubMed]

15. Porchia, M.; Pellei, M.; Del Bello, F.; Santini, C. Zinc Complexes with Nitrogen Donor Ligands as Anticancer Agents. Molecules 2020, 25, 5814. [CrossRef]

16. Singh, N.K.; Yadav, P.N.; Kumbhar, A.A.; Pokhrel, Y.R. Anticancer potency of copper(II) complexes of thiosemicarbazones. J. Inorg. Biochem. 2020, 210, 111134. [CrossRef]

17. Salas, J.M.; Caballero, A.B.; Esteban-Parra, G.M.; Mendez-Arriaga, J.M. Leishmanicidal and Trypanocidal Activity of Metal Complexes with 1,2,4-Triazolo[1,5-a]pyrimidines: Insights on their Therapeutic Potential against Leishmaniasis and Chagas Disease. Curr. Med. Chem. 2017, 24, 2796-2806. [CrossRef]

18. Badea, M.; Uivarosi, V.; Olar, R. Improvement in the Pharmacological Profile of Copper Biological Active Complexes by Their Incorporation into Organic or Inorganic Matrix. Molecules 2020, 25, 5830. [CrossRef]

19. Lelièvre, P.; Sancey, L.; Coll, J.-L.; Deniaud, A.; Busser, B. The Multifaceted Roles of Copper in Cancer: A Trace Metal Element with Dysregulated Metabolism, but Also a Target or a Bullet for Therapy. Cancers 2020, 12, 3594. [CrossRef]

20. Łakomska, I.; Fandzloch, M. Application of 1,2,4-triazolo[1,5-a]pyrimidines for the design of coordination compounds with interesting structures and new biological properties. Coord. Chem. Rev. 2016, 327-328, 221-241. [CrossRef]

21. Rostas, A.M.; Badea, M.; Ruţă, L.L.; Farcaşanu, I.C.; Maxim, C.; Chifiriuc, M.C.; Popa, M.; Luca, M.; Čelan Korošin, N.; Cerc Korošec, R.; et al. Copper(II) complexes with mixed heterocycle ligands as promising antibacterial and antitumor species. Molecules 2020, 25, 3777. [CrossRef]

22. Méndez-Arriaga, J.M.; Oyarzabal, I.; Martín-Montes, Á.; García-Rodríguez, J.; Quirós, M.; Sánchez-Moreno, M. First example of antiparasitic activity influenced by thermochromism: Leishmanicidal evaluation of 5,7-dimethyl-1,2,4-triazolo[1,5-a]pyrimidine metal complexes. Med. Chem. 2020, 16, 422-430. [CrossRef] [PubMed]

23. Caballero, A.B.; Rodríguez-Dieguez, A.; Quiros, M.; Salas, J.M.; Huertas, O.; Ramírez-Macías, I.; Olmo, F.; Marín, C.; Chaves-Lemaur, G.; Gutierrez-Sánchez, R.; et al. Triazolopyrimidine compounds containing first-row transition metals and their activity against the neglected infectious Chagas disease and leishmaniasis. Eur. J. Med. Chem. 2014, 85, 526-534. [CrossRef] [PubMed]

24. Méndez-Arriaga, J.M.; Rodríguez-Diéguez, A.; Sánchez-Moreno, M. In vitro leishmanicidal activity of copper (II) 5,7-dimethyl1,2,4-triazolo[1,5-a]pyrimidine complex and analogous transition metal series. Polyhedron 2020, 176, 114272. [CrossRef]

25. Méndez-Arriaga, J.M.; Oyarzabal, I.; Escolano, G.; Rodríguez-Diéguez, A.; Sánchez-Moreno, M.; Salas, J.M. In vitro leishmanicidal and trypanocidal evaluation and magnetic properties of 7-amino-1,2,4-triazolo[1,5-a]pyrimidine Cu(II) complexes. J. Inorg. Biochem. 2018, 180, 26-32. [CrossRef] [PubMed]

26. Méndez-Arriagaa, J.M.; Esteban-Parraa, G.M.; Juárezb, M.J.; Rodríguez-Diégueza, A.; Sánchez-Morenoc, M.; Isac-Garcíad, J.; Salas, J.M. Antiparasitic activity against trypanosomatid diseases and novel metal complexes derived from the first time characterized 5-phenyl-1,2,4-triazolo[1,5-a]pyrimidi-7(4H)-one. J. Inorg. Biochem. 2017, 175, 217-224. [CrossRef]

27. Esteban-Parra, G.M.; San Sebastián, E.; Cepeda, J.; Sánchez-Gonzálezc, C.; Rivas-García, L.; Llopis, J.; Aranda, P.; Sánchez-Moreno, M.; Quirós, M.; Rodríguez-Diéguez, A. Anti-diabetic and anti-parasitic properties of a family of luminescent zinc coordination compounds based on the 7-amino-5-methyl-1,2,4-triazolo[1,5-a]pyrimidine ligand. J. Inorg. Biochem. 2020, 212, 111235. [CrossRef]

28. Boutaleb-Charki, S.; Marín, C.; Maldonado, C.R.; Rosales, M.J.; Urbano, J.; Guitierrez-Sánchez, R.; Quirós, M.; Salas, J.M.; Sánchez-Moreno, M. Copper (II) Complexes of [1,2,4]Triazolo[1,5-a]Pyrimidine Derivatives as Potential Anti-Parasitic Agents. Drug Met. Lett. 2009, 3, 35-44. [CrossRef] 
29. Caballero, A.B.; Marín, C.; Ramírez-Macías, I.; Rodríguez-Diéguez, A.; Quirós, M.; Salas, J.M.; Sánchez-Moreno, M. Structural consequences of the introduction of 2,2'-bipyrimidine as auxiliary ligand in triazolopyrimidine-based transition metal complexes. In vitro antiparasitic activity. Polyhedron 2012, 33, 137-144. [CrossRef]

30. Calu, L.; Badea, M.; Cerc Korošec, R.; Bukovec, P.; Daniliuc, C.C.; Chifiriuc, M.C.; Măruțescu, L.; Ciulică, C.; Şerban, G.; Olar, R. Thermal behaviour of some novel biologically active complexes with a triazolopyrimidine pharmacophore. J. Therm. Anal. Calorim. 2017, 127, 697-708. [CrossRef]

31. Olar, R.; Calu, L.; Badea, M.; Chifiriuc, M.C.; Bleotu, C.; Velescu, B.; Stoica, O.; Ioniţă, G.; Stanică, N.; Silvestro, L.; et al. Thermal behaviour of some biologically active species based on complexes with a triazolopyrimidine pharmacophore. J. Therm. Anal. Calorim. 2017, 127, 685-696. [CrossRef]

32. Badea, M.; Calu, L.; Celan Korosin, N.; David, I.G.; Chifiriuc, M.C.; Bleotu, C.; Ioniţă, G.; Silvestro, L.; Maurer, M.; Olar, R. Thermal behaviour of some biological active perchlorate complexes with a triazolopyrimidine derivative. J. Therm. Anal. Calorim. 2018, 134, 665-677. [CrossRef]

33. Ruta, L.L.; Farcasanu, I.C.; Bacalum, M.; Răileanu, M.; Rostas, A.M.; Daniliuc, C.G.; Chifiriuc, M.C.; Măruțescu, L.; Popa, M.; Badea, M.; et al. Biological activity of triazolopyrimidine copper(II) complexes modulated by an auxiliary N-N-chelating heterocycle ligands. Molecules 2021, 26, 6772. [CrossRef] [PubMed]

34. Salas, J.M.; Romero, M.A.; Rahmani, A.; Faure, R. Dichlorobis(5,7-dimethyl[1,2,4]triazolo[1,5-a]pyrimidine-N3)zinc(II). Acta Cryst. 1994, C50, 510-512. [CrossRef]

35. Nakamoto, K. Infrared and Raman Spectra of Inorganic and Coordination Compounds, Part B, Applications in Coordination, Organometallic, and Bioinorganic Chemistry, 6th ed.; John Wiley \& Sons: Hoboken, NJ, USA, 2009; pp. 107-110.

36. Lever, A.B.P. Inorganic Electronic Spectroscopy; Elsevier: Amsterdam, The Netherlands, 1986; pp. 555-572.

37. Łakomska, I.; Fandzloch, M.; Popławska, B.; Sitkowski, J. Platinum(II) complexes with 5,7-disubstituted-1,2,4-triazolo [1,5a]pyrimidines: Spectroscopical characterization and cytotoxic activity in vitro. Spectrochim. Acta Part A Mol. Biomol. Spectroscop. 2012, 91, 126-129. [CrossRef]

38. Wada, A.; Jitsukawa, K.; Masuda, H. Superoxide Disproportionation Driven by Zinc Complexes with Various Steric and Electrostatic Properties. Angew. Chem. 2013, 125, 12519-12523. [CrossRef]

39. Ruan, B.-F.; Liang, Y.-K.; Liu, W.-D.; Wu, J.-Y.; Tian, Y.-P. Synthesis, characterization, and antitumor activities of two copper(II) complexes with pyrazole derivatives. J. Coord. Chem. 2012, 65, 2127-2134. [CrossRef]

40. Mariani, D.; Ghasemishahrestani, Z.; Freitas, W.; Pezzuto, P.; Costa-da-Silva, A.C.; Tanuri, A.; Kanashiro, M.M.; Fernandes, C.; Horn, A., Jr.; Pereira, M.D. Antitumoral synergism between a copper(II) complex and cisplatin improves in vitro and in vivo anticancer activity against melanoma, lung and breast cancer cells. Biochim. Biophys. Acta 2021, 1865, 129963. [CrossRef]

41. Fujita, K.; Kim, Y.H.; Kanai, O.; Yoshida, H.; Mio, T.; Hirai, T. Emerging concerns of infectious diseases in lung cancer patients receiving immune checkpoint inhibitor therapy. Respir. Med. 2019, 146, 66-70. [CrossRef]

42. Liu, Z.; Liu, T.; Zhang, X.; Si, X.; Wang, H.; Zhang, J.; Huang, H.; Sun, X.; Wang, J.; Wang, M.; et al. Opportunistic infections complicating immunotherapy for non-small cell lung cancer. Thoracic Cancer 2020, 11, 1689-1694. [CrossRef] [PubMed]

43. Cheng, W.Y.; Wu, C.; Yu, J. The role of gut microbiota in cancer treatment: Friend or foe? Gut 2020, 69, 1867-1876. [CrossRef]

44. Nham, E.; Huh, K.; Cho, S.Y.; Chung, D.R.; Peck, K.R.; Lee, N.Y.; Kang, C.I. Characteristics and Clinical Outcomes of ExtendedSpectrum beta-lactamase-producing Klebsiella pneumoniae Bacteremia in Cancer Patients. Infect. Chemother. 2020, 52, 59-69. [CrossRef] [PubMed]

45. Regiel-Futyra, A.; Dąbrowski, J.M.; Mazuryk, O.; Śpiewak, K.; Kyzioł, A.; Pucelik, B.; Brindell, M.; Stochel, G. Bioinorganic antimicrobial strategies in the resistance era. Coord. Chem. Rev. 2017, 351, 76-117. [CrossRef]

46. Lepecq, J.B.; Paoletti, C. A fluorescent complex between ethidium bromide and nucleic acids: Physical—Chemical characterization. J. Mol. Biol. 1967, 27, 87-106. [CrossRef]

47. Jiang, Q.; Xiao, N.; Shi, P.; Zhu, Y.; Guo, Z. Design of artificial metallonucleases with oxidative mechanism. Coord. Chem. Rev. 2007, 251, 1951-1972. [CrossRef]

48. Zareia, L.; Asadia, Z.; Dusekb, M.; Eignerb, V. Homodinuclear Ni (II) and Cu (II) Schiff base complexes derived from $o$-vanillin with a pyrazole bridge: Preparation, crystal structures, DNA and protein (BSA) binding, DNA cleavage, molecular docking and cytotoxicity study. J. Photochem. Photobiol. A Chem. 2019, 374, 145-160. [CrossRef]

49. Fischer, G. 1,2,4-Triazolo[1,5-a]pyrimidines. Adv. Heterocycl. Chem. 1993, 57, 81-138.

50. Stoe E Cie; Stoe \& Cie: Darmstadt, Germany, 2002.

51. Sheldrick, G.M. SHELXL-97, Program for Crystal Structure Refinement; University of Göttingen: Göttingen, Niemcy, 1998.

52. Prodan, A.M.; Iconaru, S.L.; Chifiriuc, C.M.; Bleotu, C.; Ciobanu, C.S.; Motelica-Heino, M.; Sizaret, S.; Predoi, D. Magnetic Properties and Biological Activity Evaluation of Iron Oxide Nanoparticles. J. Nanomater. 2013, 2013, 893970. [CrossRef]

53. Bilcu, M.; Grumezescu, A.M.; Oprea, A.E.; Popescu, R.C.; Mogoșanu, G.D.; Hristu, R.; Stanciu, G.A.; Mihailescu, D.F.; Lazar, V.; Bezirtzoglou, E.; et al. Efficiency of Vanilla, Patchouli and Ylang Ylang Essential Oils Stabilized by Iron Oxide@C-14 Nanostructures against Bacterial Adherence and Biofilms Formed by Staphylococcus aureus and Klebsiella pneumoniae Clinical Strains. Molecules 2014, 19, 17943-17956. [CrossRef] 
54. Gheorghe, I.; Tatu, A.L.; Lupu, I.; Thamer, O.; Cotar, A.I.; Pircalabioru, G.G.; Popa, M.; Cristea, V.C.; Lazar, V.; Chifiriuc, M.C. Molecular characterization of virulence and resistance features in Staphylococcus aureus clinical strains isolated from cutaneous lesions in patients with drug adverse reactions. Rom. Biotechnol. Lett. 2017, 22, 12321-12327.

55. Ferreira, B.J.; Brandão, P.; Meireles, M.; Martel, F.; Correia-Branco, A.; Fernandes, D.M.; Santos, T.M.; Félix, V. Synthesis, structural characterization, cytotoxic properties and DNA binding of a dinuclear copper(II) complex. J. Inorg. Biochem. 2016, 161, 9-17. [CrossRef]

56. Ma, T.; Xu, J.; Wang, Y.; Yu, H.; Yang, Y.; Liu, Y.; Ding, W.; Zhu, W.; Chen, R.; Ge, Z.; et al. Ternary copper(II) complexes with amino acid chains and heterocyclic bases: DNA binding, cytotoxic and cell apoptosis induction properties. J. Inorg. Biochem. 2015, 144, 38-46. [CrossRef] [PubMed] 